\title{
Models in Catalysis
}

\author{
Joachim Sauer $\cdot$ Hans-Joachim Freund
}

Received: 26 September 2014/ Accepted: 1 October 2014/Published online: 14 October 2014

(C) Springer Science+Business Media New York 2014

\begin{abstract}
The paper discusses the hierarchy of model studies with increasing complexity towards an understanding of industrial catalysts under reaction conditions. We use three case studies to document the progress in systems complexity as well as the development of instruments that allow us to approach the study of acting catalysts: magnesium oxide clusters in the gas phase, gold nanoparticles on metal oxide surfaces, and palladium nanoparticles compared to crystal surfaces. While the examples are from the field of heterogeneous catalysis, we discuss the relation to homogeneous and enzymatic catalysis.
\end{abstract}

Keywords Model systems - Heterogeneous catalysis . Catalysis - Computational chemistry $\cdot$ Theory $\cdot$ Surface science Electron transfer

\section{Introduction}

In a philosophical sense, a model is a restricted representation of reality. In some contexts, such as architecture, models are miniature replicas of what the finished building will look like and how it will integrate in its surroundings.

Dedicated to Johannes Lercher on the occasion of his 60th birthday on September 20, 2014.

\section{J. Sauer}

Institut für Chemie, Humboldt Universität zu Berlin, Unter den

Linden 6, 10099 Berlin, Germany

H.-J. Freund $(\bowtie)$

Fritz-Haber Institut der Max-Planck Gesellschaft, Faradayweg

4-6, 14195 Berlin, Germany

e-mail: freund@fhi-berlin.mpg.de
In other contexts, such as economy, models are highly idealized descriptions of phenomena that do not exist in nature. In physics, for example, gases are modeled by infinitesimally small molecules, which exhibit no forces acting between them. However, in fact, we know that molecules have a finite size and forces act between them. These types of models share a common feature: although models neglect certain features to stress essential aspects, we know how to add corrections to the model to bring it closer to reality.

So, what do we mean by models in catalysis? Here we have to look at the phenomenon of catalysis first. Catalysis is a kinetic phenomenon, where a material (the catalyst) changes the rate of a chemical reaction without being part of the products $[1,2]$. This is Ostwald's definition put forward during the nineteenth century [3]. Most frequently in catalytic literature we encounter "micro-kinetic models" which describe the complex system of elementary reaction and transport steps by a limited, ideally minimum set of rate equations [4]. This important aspect is not subject of the present article.

Here we focus on models for the catalytic material. Catalysis may occur under various circumstances: When it occurs at the interface between a solid and a gas or liquid phase we call it heterogeneous catalysis, when it occurs in the liquid phase we call it homogeneous catalysis and when it occurs under the action of an enzyme, which is often a big biologically relevant molecule in the liquid phase we call it enzymatic catalysis. Since the catalyst is not part of the products it makes no sense to look at the catalytic material before and after the catalytic action, unless the reaction does not change the properties of the catalytic material. We really need to look at the material as it performs its action. This is an experimental challenge that has, so far, not been fully met. Since a discovery of a catalytic 
material has often been based on serendipity, and its optimization on trial and error, it may not be trivial to identify the most important ingredients, even without the reaction-induced changes. One approach to overcome this problem is to use a systematic model approach [5, 6]! Take heterogeneous catalysis as an example: A reaction between two gaseous components proceeds at the surface of a material containing several components. In order to identify the active part of the material we need to be able to study a very small amount of starting material and of products at the surface of the complex material, and we need to be simultaneously able to differentiate the surface of the material from its bulk. This requires the development of specific, surface sensitive techniques and, in order to isolate the action of the various material components, a systematic variation in the complexity of the studied material [7]. This variation has to proceed from the most simple to the more complex, and not vice versa. Only by adding complexity will we be able to finally approach the final real system. In this sense, we set up model systems in catalysis, which may be characterized at the atomic level. There are several levels of models in catalysis, which we try to show as a flow chart in Fig. 1, both, for theory and experiment.

We look at experiment and theory separately, knowing, however, that progress in the spirit of understanding phenomena at the atomic level will only be achieved by going hand-in-hand. We are trying to approach the situation encountered on the real working catalyst and-although it is not always possible-characterization-down to the detail necessary-by following an axis of increasing complexity. We clearly move, as outlined above from the simple to the complex, and not vice versa, which is important. The chart is only made up to look complete, while in reality it is not, since, as indicated above, characterization of the working catalyst is not really possible at present, and it is this missing knowledge that justifies the entire approach. We believe to know the ingredients of the working catalyst and may verify it to a certain extent by our arsenal of characterization tools, but to unravel how they interact and perform can only be taken apart by systematically increasing the complexity, hoping to mimic the observation on the working catalyst.

The bottom of the chart refers to clusters in the gas phase in different charge states. Through a comparison or better a combination between experiment and theory it is possible to unravel details of the reactions taking place in such systems. It has, indeed, been possible to see catalytic reactions, characterized by turnover, on those materials, and this is a first step-The "Ultimate Single Site Catalysis" [8]. The small window indicates, that systems at this level of complexity have been investigated in uhv/ambient molecule level in gas phase and/or in interaction with a gas

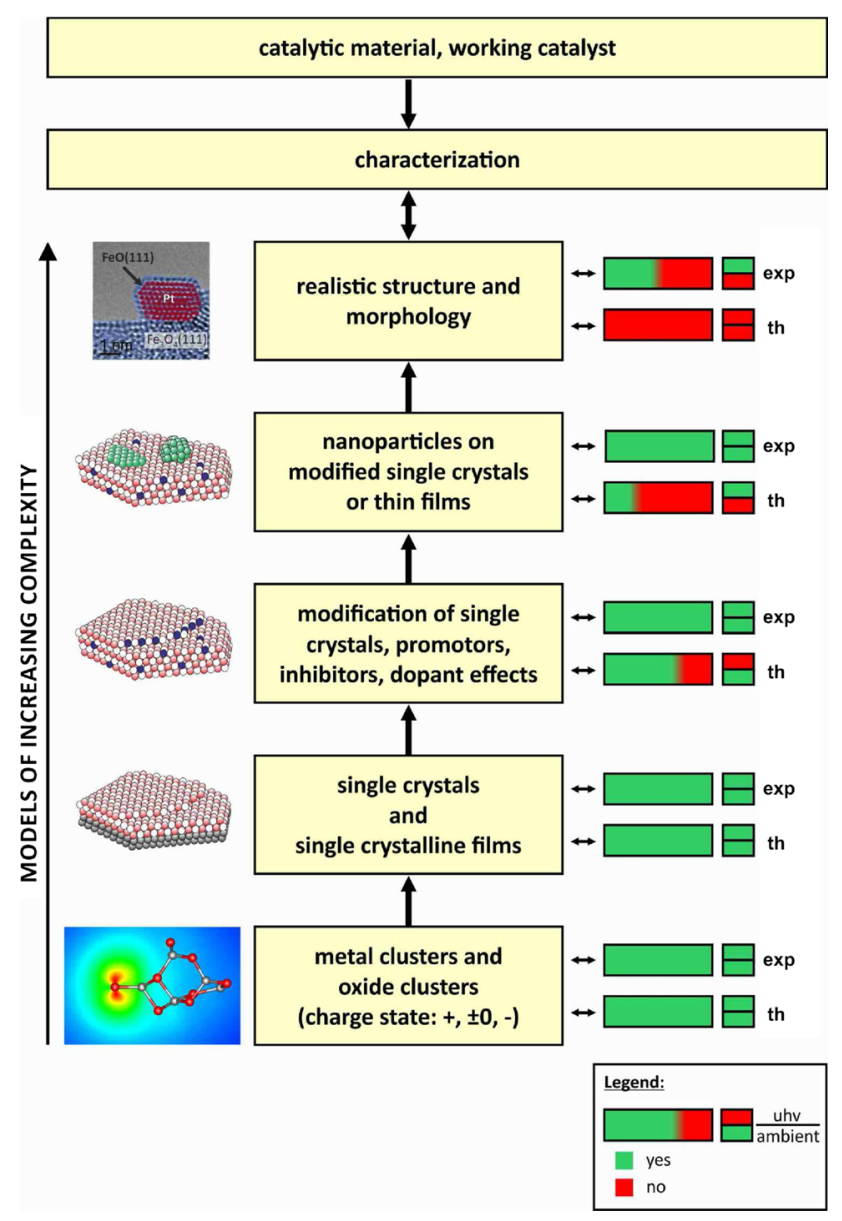

Fig. 1 Schematic and pictorial representation of model systems as a function of increasing complexity to capture the essential features of a working catalyst. Each level is evaluated with respect to experiment and theory and with respect to progress that has been made to achieve a proper representation/description of each level: green: yes, achieved; red: no, not achieved. In addition, it is indicated whether studies have been performed under UHV and under ambient conditions

phase/crossed beams. However, the distance in complexity of the isolated cluster level with respect to supported clusters is far, and the size of clusters, possible to study, has, until now, been limited, although steadily increasing. Having said this, still very useful and unique information on details of reaction mechanisms may be unraveled. At the next level in the chart (Fig. 1), single crystal and wellordered thin film surfaces have been used successfully in the past to start to understand fundamental phenomena at surfaces. This culminated in the Nobel Prize for Gerhard Ertl in 2007 [9, 10]. Given the enormous success of those studies, the valid question that has been asked is: What comes next? In fact, not too long ago, people have argued: Surface science is dead!! We believe, it is clear from what we argued so far that this statement is definitely wrong, if one is interested in unraveling the details of catalytic 
reactions. But not only in this respect! Single crystal metal studies lack important ingredients of real catalysts: One is the finite size of the metal particles, typically used in the catalyst, and, secondly, the oxide-metal interface realized by the fact that dispersed metals are typically supported on oxides, which, according to all reports so far, is of enormous importance for the reactions, their activity and selectivity, observed. Not to speak of the addition of modifiers such as poisons or promoters. So we certainly have to move to higher levels of model studies as shown in Fig. 1 before we will have a chance to reach a level, which may be directly compared and connected to situations encountered on real catalytic material. This is the point where the two arrows bottom up and top down meet. Through the interplay between experiment and theory, those additional ingredients, indeed, have been identified as essential, and it is the task of researchers in the field, both from theory and experiment, to work together to bring the field forward along the complexity axis shown in Fig. 1. Next to the various levels of complexity, the partially green and red bars indicate how far theory and experiment have come in an effort to describe systems at those levels of complexity properly. Also, it is important to indicate whether studies have been possible under uhv conditions and in addition comparison has been made to in situ studies under ambient conditions. This is indicated by the little window.

While for experiment, as we change the level of complexity, the number of components change, the kind of experiments employed are the same. For theory and computations, on the other hand, different types of approaches are relevant. Only the simplest experimental model catalysts, such as gas phase clusters and single crystal surfaces may be directly studied by quantum methods yet including ambient conditions, whereas the treatment of more complex structures requires adopting computational models such as embedded cluster models or periodic models [11]. Last but not least, quantum chemical calculations always require approximations. In his Nobel lecture John Pople describes "Quantum Chemical Models" [12] as a hierarchic approach to better approximations. At each model level there is a well-defined set of approximations whose performance for different types of chemical compounds has been empirically tested.

We will try to exemplify the approach of experimental and computational model systems by choosing a number of examples, which the authors have partly worked on jointly, using a variety of experimental and theoretical techniques. The examples are basically taken from heterogeneous catalysis, but, at the end of this article we will comment on the other two areas of interest, i.e. homogeneous catalysis and enzymatic catalysis, and we will see that many aspects of the complexity encountered for heterogeneous catalysis also need to be addressed for homogeneous catalysis and enzymatic catalysis, even though there are claims that molecular catalysts are more easy to understand than solid catalysts. This may be true to some extent, but when we look at the full complexity of the situation, all three subfields are at the same stage of knowledge pretty much. The more important it is to try to unify approaches, a goal that a cluster of excellence in Berlin between the three Berlin Universities and two Max-Planck Institutes in the Berlin area try to tackle.

\subsection{Example \#1: Gas Phase Reactivity of Metal Oxide Clusters}

Gas phase clusters offer the possibility to study the active site in isolation. A species as small as the diatomic magnesium oxide cation radical, $\mathrm{MgO}^{+}$, has been shown to activate the $\mathrm{C}-\mathrm{H}$ bond of methane and to form methyl radicals [13]. It shares the $\mathrm{O}^{--}$radical site with the polynuclear $\left(\mathrm{Al}_{2} \mathrm{O}_{3}\right)_{4}^{+}$radical cation which has also been found to abstract hydrogen from methane and to yield methyl radicals [14]. Such $\mathrm{O}^{-}$radical sites, neighbored to $\mathrm{Li}^{+}$, have been postulated by Lunsford and coworkers [15] as the active sites on Li-doped magnesium oxide, the simplest among many solid metal oxide catalysts [16] that catalyze heterogeneously the oxidative coupling of methane,

$2 \mathrm{CH}_{4}+\mathrm{O}_{2} \rightarrow \mathrm{C}_{2} \mathrm{H}_{4}+2 \mathrm{H}_{2} \mathrm{O}$.

On Li-doping of $\mathrm{MgO}, \mathrm{Li}^{+} \mathrm{O}^{-}$formally replaces $\mathrm{Mg}^{2+} \mathrm{O}^{2-}$ [17], and the reaction is initiated by hydrogen abstraction from methane at the oxygen radical sites [18],

$\mathrm{H}_{3} \mathrm{C}-\mathrm{H}+\left[\mathrm{O}^{-} \mathrm{Li}^{+}\right]_{\mathrm{MgO}} \rightarrow \mathrm{H}_{3} \mathrm{C}+\left[\mathrm{HO}^{-} \mathrm{Li}^{+}\right]_{\mathrm{MgO}}$

An obvious choice for a gas phase model would thus be a $(\mathrm{MgO})_{\mathrm{n}} \mathrm{Li}^{+} \mathrm{O}^{-}$gas phase cluster. Unfortunately, gas phase reactivity studies on neutral clusters are difficult, and the majority of experiments are mass spectrometric studies on charged species [19]. Since on ionization of a pure $\mathrm{MgO}$ cluster the same oxygen radical species is created as present in Li-doped $\mathrm{MgO}$, cationic $\mathrm{MgO}$ clusters are valid and viable models for gas phase reactivity studies. Figure 2 shows how quantum mechanics can help to bridge the gap between surface models and gas phase models. While Lidoped $\mathrm{MgO}$ can be experimentally studied as powder catalysts or thin film model system and cationic gas phase clusters can be studied in mass spectrometric experiments, computational methods based on quantum mechanics can treat all the different systems on equal footing and, hence, help bridging the gap between the different experiments.

To examine the active site at terraces, steps or corners we applying periodic boundary conditions to large super cells or embed geometrically constraint clusters in their crystal environment [21]. Computationally, we can also 


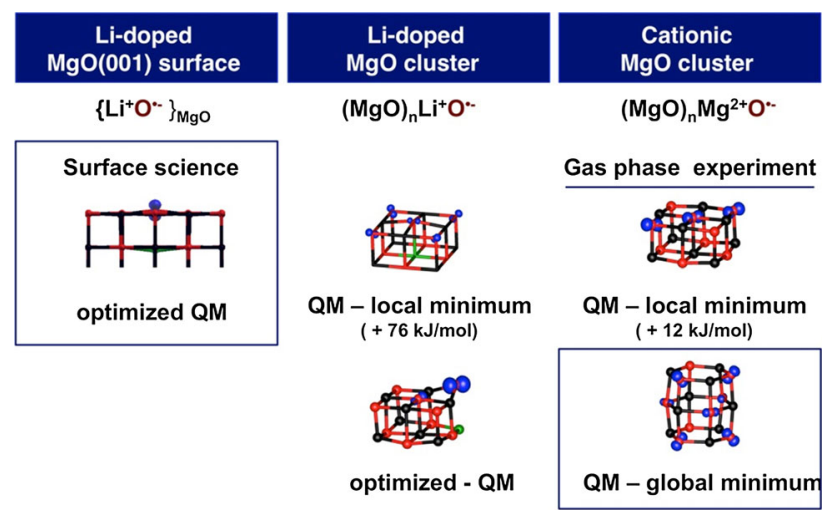

Fig. 2 Quantum mechanics helps bridging the gap between thin film models (or powder catalysts) and gas phase models for Li-doped oxides. For the gas phase clusters, both local minimum structures and global minimum structures are shown [20]. Their energy difference is given in parenthesis, Color code: $\mathrm{O}-$ red, $\mathrm{Mg}$-black, $\mathrm{Li}-$ green. Spin density is shown in blue

study neutral Li-doped clusters and compare the results with those for cationic pure $\mathrm{MgO}$ clusters. The structure type of cationic gas phase clusters can be very different from that of the bulk solid [22], and the calculations may be performed for the most stable (global minimum) structure or the local minimum structure that resembles the rock salt structure of $\mathrm{MgO}$. Figure 2 shows that this has consequences, for example, on the spin density distribution.

Density functional theory has been used (B3LYP functional) to determine the energy profile for hydrogen transfer from the $\mathrm{C}-\mathrm{H}$ bond to the oxygen radical site in the different model systems [21-23]. Figure 3 shows the transition structures localized on the potential energy surface and their energies with respect to methane separated from the catalyst, i.e., the apparent energy barriers.

The first conclusion is that the cationic pure magnesium oxide clusters indeed show the same reactivity as the Lidoped neutral clusters. The barriers of the $(\mathrm{MgO})_{\mathrm{n}}^{+}$clusters, 20,23 , and $6 \mathrm{~kJ} / \mathrm{mol}$ for $\mathrm{n}=2,4,7$, respectively [23], are in a very similar range as the values of 11,23 , and $19 \mathrm{~kJ} /$ mol for the neutral $\mathrm{LiO}(\mathrm{MgO})_{\mathrm{n}-1}$ clusters with $\mathrm{n}=4,6$, and 9 , respectively. The calculated barrier for the surface model is also very close, $27 \mathrm{~kJ} / \mathrm{mol}$ [21], showing that the gas phase clusters are indeed useful models for studying the reactivity of oxygen radical sites as they may occur on $\mathrm{Li}$-doped $\mathrm{MgO}$. Figure 3 reveals an important detail of the computational modeling. The correct solid state result is only obtained from cluster models, if they are properly electrostatically embedded and a sufficient number of atoms is relaxed. Just putting geometric constraints on the models yields to high barriers $(61 \mathrm{~kJ} / \mathrm{mol})$. If a cluster of the same size is allowed to assume its lowest energy structure, the active $\mathrm{Li}^{+} \mathrm{O}^{-}$site accommodates at corner sites.

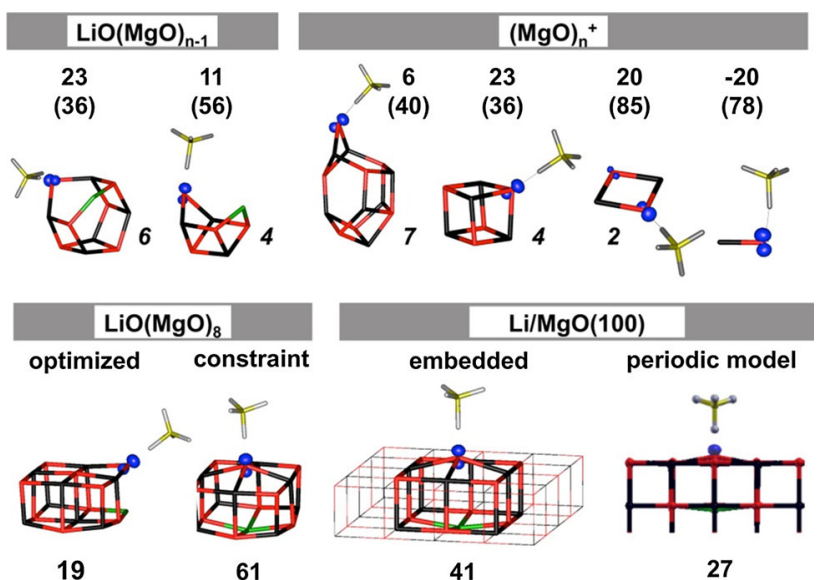

Fig. 3 Transition structures for hydrogen abstraction from methane on different gas phase cluster models, neutral Li-doped magnesium oxide clusters and magnesium oxide cluster cations, as well as embedded cluster and periodic models for $\mathrm{Li}$-doped $\mathrm{MgO}(001)$. The numbers are B3LYP/TZVP apparent energy barriers in $\mathrm{kJ} / \mathrm{mol}$ (intrinsic barriers in parenthesis). Numbers in italics specify the cluster size n. See Fig. 2 for the color code

When comparison with mass spectrometric experiments was made, it was found that the dimer cation, $(\mathrm{MgO})_{2}^{+}$does not react with methane [24], and neither do larger cations. It needs an alkane with a more reactive $\mathrm{C}-\mathrm{H}$ bond, e.g. propane, to observe hydrogen transfer. With methane, this reaction is only observed for the diatomic $\mathrm{MgO}^{+}$radical cation, for which a negative apparent barrier is predicted. For all larger $(\mathrm{MgO})_{\mathrm{n}}^{+}$cations and all neutral $\mathrm{LiO}(\mathrm{MgO})_{\mathrm{n}-1}$ clusters the energy of the transition structure is above the energy of the reactants and no reaction is observed.

Here, we encounter a fundamental difference between reactions in thermally equilibrated condensed phases where the system can overcome substantial barriers depending on temperature, and gas phase reactions, where crossing a barrier is only possible if the energy of the transition state is below the energy of the reactants, at least under single collision conditions. This perfectly explains the results of the mass spectrometric experiments. For all systems for which quantum chemical calculations predict a negative apparent barrier the reaction has been observed, for the others not (Fig. 4). This is an important lesson as it tells us that the applied methodology-B3LYP density functional with a sufficiently flexible triple-zeta valence plus polarization (TZVP) basis set-is a suitable method on which we can rely also for surface studies.

Gas phase models have an additional advantage. Their limited size of the makes it possible, to apply much better, more reliable, wave-function-based methods allowing an assessment of the density functionals used for large, periodic systems. For example, coupled cluster calculations for $\mathrm{CH}_{4} / \mathrm{MgO}^{+}$and $\mathrm{CH}_{4} /(\mathrm{MgO})_{2}^{+}$show that the B3LYP/TZVP 
results are affected by errors of +1.3 and $-6.5 \mathrm{~kJ} / \mathrm{mol}$, respectively, almost within the chemical accuracy range of $\pm 4.2 \mathrm{~kJ} / \mathrm{mol}(\approx 1 \mathrm{kcal} / \mathrm{mol})[23]$.

In summary, from experiments on gas phase models when combined with quantum chemical calculations we learn that oxygen radical species in metal oxides are actives sites for hydrogen abstraction from $\mathrm{C}-\mathrm{H}$ bonds and that density functional theory yields accurate barriers (with errors smaller than $6.5 \mathrm{~kJ} / \mathrm{mol}$ ) when the B3LYP hybrid functional is applied.

For surface sites of Li-doped $\mathrm{MgO}$ the apparent energy barrier will be affected by dispersion interactions between methane and the oxide surface. If this is taken into account, and if it is also taken into account that oxygen radical sites may not only be located at terrace sites, but also at corner sites, the conclusion is reached that the apparent barrier should be between $7 \pm 6$ and $27 \pm 6 \mathrm{~kJ} / \mathrm{mol}$ which is in obvious conflict with the much higher observed values, between 85 and $160 \mathrm{~kJ} / \mathrm{mol}$. From $\mathrm{CH}_{4} / \mathrm{CD}_{4}$ isotope exchange experiments a barrier of $85 \mathrm{~kJ} / \mathrm{mol}$ has been deduced for $\mathrm{C}-\mathrm{H}$ bond activation [25], while $90 \mathrm{~kJ} / \mathrm{mol}$ have been reported for $\mathrm{C} 2$ hydrocarbon formation in OCM reactions [26]. From microkinetic schemes fitted to kinetic OCM data, a barrier as high as $147 \mathrm{~kJ} / \mathrm{mol}$ has been deduced for the generation of methyl radicals by hydrogen abstraction [27]. The activity of Li-doped $\mathrm{MgO}$ catalysts was found to vary strongly over the catalytic runs and depend also on the preparation conditions [21, 28]. The reported barriers for the stationary state of the catalysts were $90-160 \mathrm{~kJ} / \mathrm{mol}$ [28] and $133 \mathrm{~kJ} / \mathrm{mol}$ [21].

From this disagreement the conclusion was reached that the $\mathrm{Li}^{+} \mathrm{O}^{-}$site is not the active site, and that methyl radicals released into the gas phase are not formed by hydrogen transfer to such sites. We stress that it would not have been possible to reach this conclusion without the experiments and calculations on gas phase models. Further studies have shown that the Lunsford mechanism needs to be revised and that $\mathrm{CH}_{4}$ chemisorbs heterolytically on morphological defects [21].

$$
\begin{aligned}
& {\left[\mathrm{Mg}^{2+} \mathrm{O}^{2-}\right]_{\mathrm{MgO}}+\mathrm{H}-\mathrm{CH}_{3}+\mathrm{O}_{2}} \\
& \quad \rightarrow\left(\mathrm{O}_{2}^{--}\right)\left[\mathrm{HO}^{-} \mathrm{Mg}^{2+}\right]_{\mathrm{MgO}}+\mathrm{CH}_{3}
\end{aligned}
$$

Since the OCM activity is also found for $\mathrm{Li}$-free $\mathrm{MgO}$, the question emerged of what the role of Li could be. Here thin film models proved crucial as they were providing evidence about the role of Li-dopants for restructuring $\mathrm{MgO}$ which features more steps and corners [29]. Gas phase clusters are useful model systems for catalysis if they feature the same active site as solid catalysts, enzymes or molecular catalysts. The use of charged, in particular cationic clusters can be helpful, because the stronger binding onto the substrate (the molecule to be catalytically

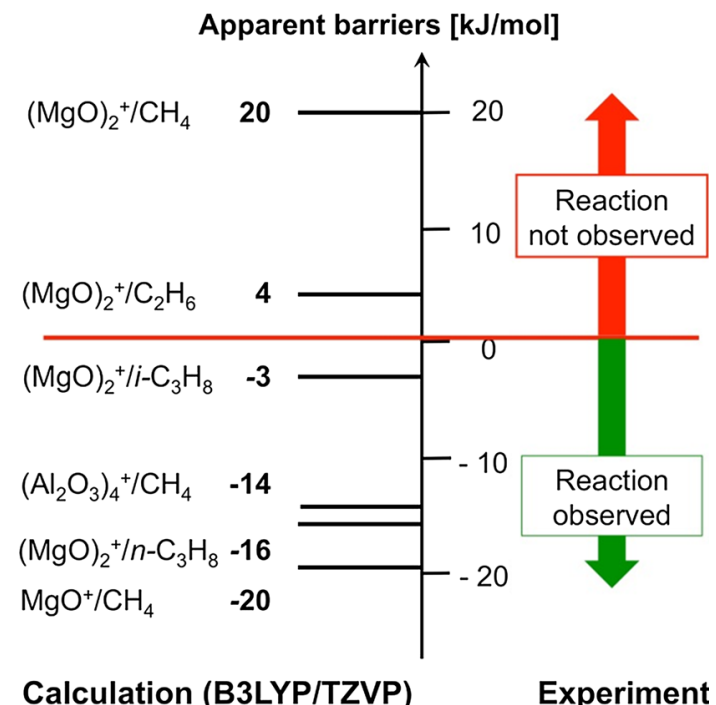

Fig. 4 Calculated apparent energy barriers for hydrogen abstraction from $\mathrm{C}-\mathrm{H}$ bonds by metal oxide cations of different size. DFTCalculations (B3LYP/TZVP) from Ref. [23], experiments see Ref. [24]

converted) may lower the apparent barrier and make the gas phase reaction feasible. Care must be taken, however, that taking out an electron does not change the nature of the active site. In the above example creating cation in the gas phase $\mathrm{MgO}$ cluster created the same oxygen radical, $\mathrm{O}^{-}$, species as is created in the solid material by Li-doping.

This has been also demonstrated for vanadium oxide supported on oxides, a catalyst for selective oxidations. Vanadyl groups, $\mathrm{O}=\mathrm{V}(\mathrm{O}-)_{3}$ have been identified as active sites [30], and two different types of cationic clusters have been used for gas phase studies. The $\mathrm{V}_{4} \mathrm{O}_{10}^{+}$radical cation proved highly reactive, abstracting hydrogen easily from methane [31], while the closed shell $\mathrm{V}_{3} \mathrm{O}_{7}{ }^{+}$species showed similar reactivity as the surface species [32]. Although it was not reactive enough to activate a $\mathrm{C}-\mathrm{H}$ bond of propane in the gas phase, but hydrogen abstraction from butene could be observed [33] The reactivity differences between the two gas phase species have been explained and can be predicted using a simple reactivity descriptor, the vanadium-oxygen bond dissociation energy or, in physical terms, the oxygen defect formation energy [34], which is $277-287 \mathrm{~kJ} / \mathrm{mol}$ for vanadyl sites on silica supports. For the neutral $\mathrm{V}_{4} \mathrm{O}_{10}$ with a tetrahedral arrangement of four vanadyl groups, $\mathrm{O}=\mathrm{V}(\mathrm{O}-)_{3}$ it is very similar, $257 \mathrm{~kJ} / \mathrm{mol}$. On ionization, in the $\mathrm{V}_{4} \mathrm{O}_{10}^{+}$radical cation, a much weaker $\mathrm{O}^{-} \mathrm{V}^{+}(\mathrm{O}-)_{3}$ bond is created with a bond dissociation energy as low as $14 \mathrm{~kJ} / \mathrm{mol}$, while for the $\mathrm{O}=\mathrm{V}^{+}(\mathrm{O}-)_{3}$ site in $\mathrm{V}_{3} \mathrm{O}_{7}^{+}$a value of $165 \mathrm{~kJ} / \mathrm{mol}$ is obtained, of the same order of magnitude as for the surface species. 


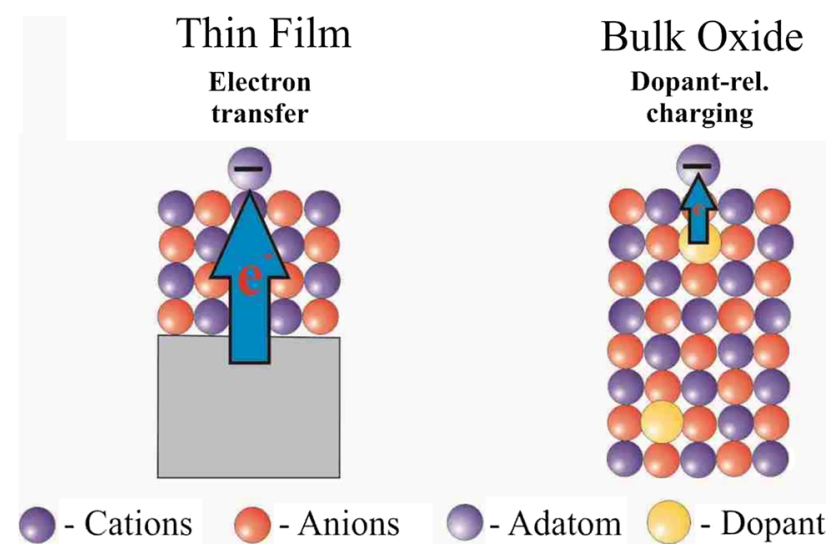

Fig. 5 Schematic representation of a two charge transfer mechanism

\subsection{Example \#2: Nanoparticles and the Metal Oxide Interface}

The studies on free clusters in the gas phase have taught us many important lessons [1]. One is that the charge-state of the system influences the chemistry of the system decisively. When anchored to a surface, a cluster or nanoparticle may change its charge state [35], and concomitantly, this site will be decisively influenced. Within a model catalyst approach one would like to design a concept that allows one to design the system and control the process of charge transfer to and from a supported nano-particle. The approach chosen is schematically shown in Fig. 5 [6].

In the left panel the electron sources or drains for electron-transfer are the oxide-metal and metal-oxide interfaces, and in the right panel a properly chosen dopant in a bulk material takes the role of the electron source. In order to systematically go through the evidences, we will start with the discussion of adsorbate properties on thin, metal-supported oxide films starting from a single atom, moving towards nano-particles, and then take those findings as reference to compare them with the situation on doped oxides. Then, we will discuss, and exemplify the consequences of general considerations in catalysis and oxidative methane coupling in particular. As a marker for charge transfer, we are using $\mathrm{Au}$ because of its large electronegativity [36].

Adsorption on defect-free insulating oxides is generally weak, given the high degree of bond saturation at their surface and the large gap that governs their electronic structure [37-42]. Metal atoms deposited onto pristine oxides have essentially two means to interact with the surface. The first one arises from van-der-Waals or dispersive forces. Depending on the atom polarizability, the resulting adsorption energies are of the order of $0.5 \mathrm{eV}$ or below for a single atom. The second interaction channel is direct overlap between orbitals of the ad-species and the oxide surface and a consecutive redistribution of charge. A combination of scanning tunneling microscopy, electron spin resonance spectroscopy, and IR-spectroscopy as shown in Fig. 6 has been used to prove this point.

The presence of single gold atoms on the surface of a thick $\mathrm{MgO}$ film was proven by STM (Fig. 6b) and investigated further by electron paramagnetic resonance (EPR) spectroscopy [40]. The latter technique for in situ surface studies has been developed at the Fritz Haber Institute [4345]. The EPR spectrum is characterized by a quartet of lines caused by the hyperfine interaction of the electron spin $(S=1 / 2)$ with the nuclear spin of the neutral gold atoms (Fig. 6a). By a full analysis of the spectral angular dependence and the additional super-hyperfine interaction with $\mathrm{O}$ of an ${ }_{17} \mathrm{O}$ enriched $\mathrm{MgO}$ film, the $\mathrm{Au}$ atoms were shown to adsorb on top of oxygen ions in agreement with theoretical predictions [46-48]. DFT calculations showed, that these observations are indicative of polarization of the singly occupied 6s orbital of neutral Au atoms away from the $\mathrm{MgO}$ surface [40]. Adsorbing probe molecules such as $\mathrm{CO}$ onto the $\mathrm{Au}$ atoms provide the opportunity to apply IR spectroscopy to this system (Fig. 6c). Two signals at 2,120 and $1852 \mathrm{~cm}^{-1}$ are observed.

The former signal can be assigned to $\mathrm{CO}$ adsorbed on small neutral $\mathrm{Au}$ clusters, whereas the latter one, redshifted by 291 and $180 \mathrm{~cm}^{-1}$ compared with gas-phase CO and the $\mathrm{Au}-\mathrm{CO}$ complex [49], respectively, is associated with single $\mathrm{Au}$ atoms. A detailed theoretical analysis of this system reveals that the large red shift is caused by the largely polarized valence electrons of the adsorbed $\mathrm{Au}$ atoms, which create an $\left(\mathrm{Au}^{+}\right)-\mathrm{CO}^{-}$-complex on the surface. It is important to note at this point again, how important the collaboration between experimentalists and theorists is. In the present case, a straightforward application of simple, heuristic concepts may have led to false conclusions, namely, that the $\mathrm{Au}$ atoms are negatively charged.

A first hint for the formation of charged adsorbates on thin oxide films came from low-temperature scanning tunneling microscopy (STM) experiments performed on a much thinner, $3 \mathrm{~mL} \mathrm{MgO/Ag(001)} \mathrm{exposed} \mathrm{to} \mathrm{small}$ amounts of $\mathrm{Au}$ [39]. Whereas on bulk oxides, gold shows a strong tendency for aggregation, mainly isolated atoms are detected on the thin film even at high gold exposure.

Charged species tend to maximize their interatomic distance in order to reduce the mutual Coulomb repulsion. A similar phenomenon was found for alkali atoms on metal and semiconductor surfaces before and was assigned to a positive charging upon adsorption [50-52]. Conversely, the $\mathrm{Au}$ atoms on the $\mathrm{MgO}$ films charge up negatively, as their 6s orbital gets filled with electrons from the $\operatorname{Ag}(001)$ support below the oxide spacer layer. The charge exchange 

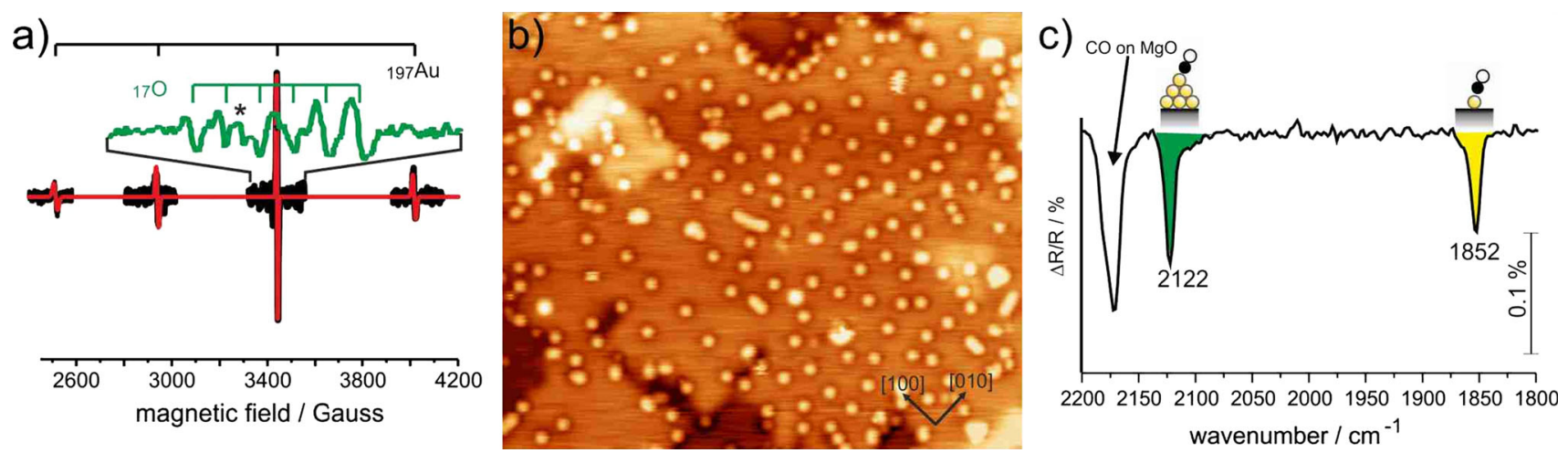

Fig. 6 a Experimental and simulated EPR spectra of $0.01 \mathrm{~mL} \mathrm{Au}$ atoms adsorbed on a $20 \mathrm{~mL}$ thick $\mathrm{MgO}(001)$ film on $\mathrm{Mo}(001)$. EPR spectrum of $\mathrm{Au}$ atoms on an ${ }_{17} \mathrm{O}$ enriched $\mathrm{MgO}$ film is shown in green. b STM image $\left(30 \times 25 \mathrm{~nm}^{2}\right)$ of $\mathrm{Au}$ atoms $(0.035 \mathrm{~mL})$

deposited at $8 \mathrm{~K}$ on $\sim 8 \mathrm{~mL}$ thick $\mathrm{MgO}(001) / \mathrm{Ag}(001)$ film. c IRspectrum of $\mathrm{CO}$ adsorbed on $\mathrm{Au}$ atoms and clusters on a $\mathrm{MgO}(001)$ film

is enabled by the high electronegativity of gold, as mentioned above, in combination with a small work function of the $\mathrm{Ag}-\mathrm{MgO}$ system [53, 54]. The experimentally deduced charging scenario was corroborated by DFT calculations yielding a computed Bader charge of -1 lel at the Au atoms in addition to the expected increase in binding energy [45].

What are the consequences of negatively charged $\mathrm{Au}$ atoms for larger $\mathrm{Au}$ particles? This question was first addressed in a theoretical paper by Pacchionis and Landmańs groups [55]: While a $\mathrm{Au}_{20}$ cluster keeps its pyramidal, three-dimensional shape when supported on bulk $\mathrm{MgO}$, the same $\mathrm{Au}_{20}$ cluster supported on a $2 \mathrm{~mL} \mathrm{MgO}$ film on Ag takes shape of a flat single layer Au raft. The reason is simply the tendency of Au to pick up electrons, which in this case stem from the $\mathrm{MgO} / \mathrm{Ag}$ interface. In order to optimize the electron transfer the $\mathrm{Au}$ atoms assume positions as close as possible to this interface, i.e. single layer Au rafts, where charge is located at the rim of the $\mathrm{Au}$ raft. We realize that electron transfer may influence the morphology of supported nano-particles and lead to charge localization at particular sites.

For flat $\mathrm{Au}$ islands on $\mathrm{MgO} / \mathrm{Ag}(001)$, STM conductance spectroscopy can be exploited to determine their charge state [56]. A particularly instructive example shows an ultra-small Au cluster with $10 \AA$ diameter and $0.8-0.9 \AA$ apparent height grown on a $2 \mathrm{~mL} \mathrm{MgO} / \mathrm{Ag}(001)$ film (Fig. 4) [56].

In low-bias STM images, mainly the cluster morphology is revealed, as no eigenstates of the aggregate are available in the probed energy window. At slightly higher bias, the apparent cluster height doubles and flowerlike protrusions emerge in the image. This bias-dependent contrast change provides evidence that tunneling is now governed by the electronic and not the topographic properties of the nanostructures. More precisely, a distinct eigenstate, the LUMO of the Au aggregate, becomes accessible to the tunneling electrons and dominates the image contrast at positive bias. A similar observation is made at negative bias, when the $\mathrm{Au}$ HOMO moves into the bias window and a comparable "nano-flower" becomes visible in the STM. The two observed quantum well states closely resemble the eigenstates of a free-electron gas confined in a 2D parabolic potential (see Ref. [56] for details). They are derived from the $\mathrm{Au}$ 6s states of the participating atoms and preserve their characteristic symmetry, as they do not mix with either the states of the wide-gap oxide or with the $\mathrm{Au} 5 \mathrm{~d}$ and $6 \mathrm{p}$ states positioned at much lower or higher energy, respectively $[57,58]$. The STM reflects not only the symmetry of eigenstates, but also their energy position. For the Au cluster shown in Fig. 7, the highest occupied eigenstate and lowest unoccupied eigenstate are clearly identified as $\mathrm{dI} / \mathrm{dV}$ peaks at -0.4 and $+0.8 \mathrm{~V}$, respectively, separated by a region of zero conductance of $1.0 \mathrm{~V}$ width (blue and cyan curves: top and left part of the cluster). The lower occupied eigenstates at -0.8 and at $-1.2 \mathrm{~V}$ are both of P-symmetry with nodal planes pointing in two orthogonal directions. With this experimental input, the electronic structure of the gold nano island and more importantly its charge state can be determined by comparing the measured orbital shapes with DFT calculations for possible sample clusters [56]. The experimental signature shown in Fig. 7 could be matched with the properties of a planar $\mathrm{Au}_{18}$ cluster. Its structure is derived from a magic-size $\mathrm{Au}_{19}$ cluster with one missing corner atom. In agreement with experiment, the highest occupied and lowest unoccupied eigenstates are of $\mathrm{G}$ symmetry (with four nodal planes). The missing atom with respect to a symmetric $\mathrm{Au}_{19}$ gives rise to a slight asymmetry in the orbital shapes that becomes particularly evident for the lowest unoccupied eigenstate. A detailed book keeping of electrons in the quantum well states requires 22 electrons to be provided. As each of the $18 \mathrm{Au}$ atoms adds only a single 6s electron 
Fig. 7 a Topographic and b dI/ $\mathrm{dV}$ image of a symmetric Au cluster on $2 \mathrm{~mL} \mathrm{MgO/Ag(001)}$ taken at the given sample bias $\left(3.9 \times 3.9 \mathrm{~nm}^{2}\right)$. b Calculated HOMO and LUMO shape, as well as structure model of an $\mathrm{Au}^{18}$ cluster on $\mathrm{MgO} / \mathrm{Ag}(001)$. Perfect match between experimental and theoretical cluster properties indicate the identity of both aggregates. c The corresponding dI/dV spectra are shown in addition (blue and cyan curves: top and left part of the cluster) [56]
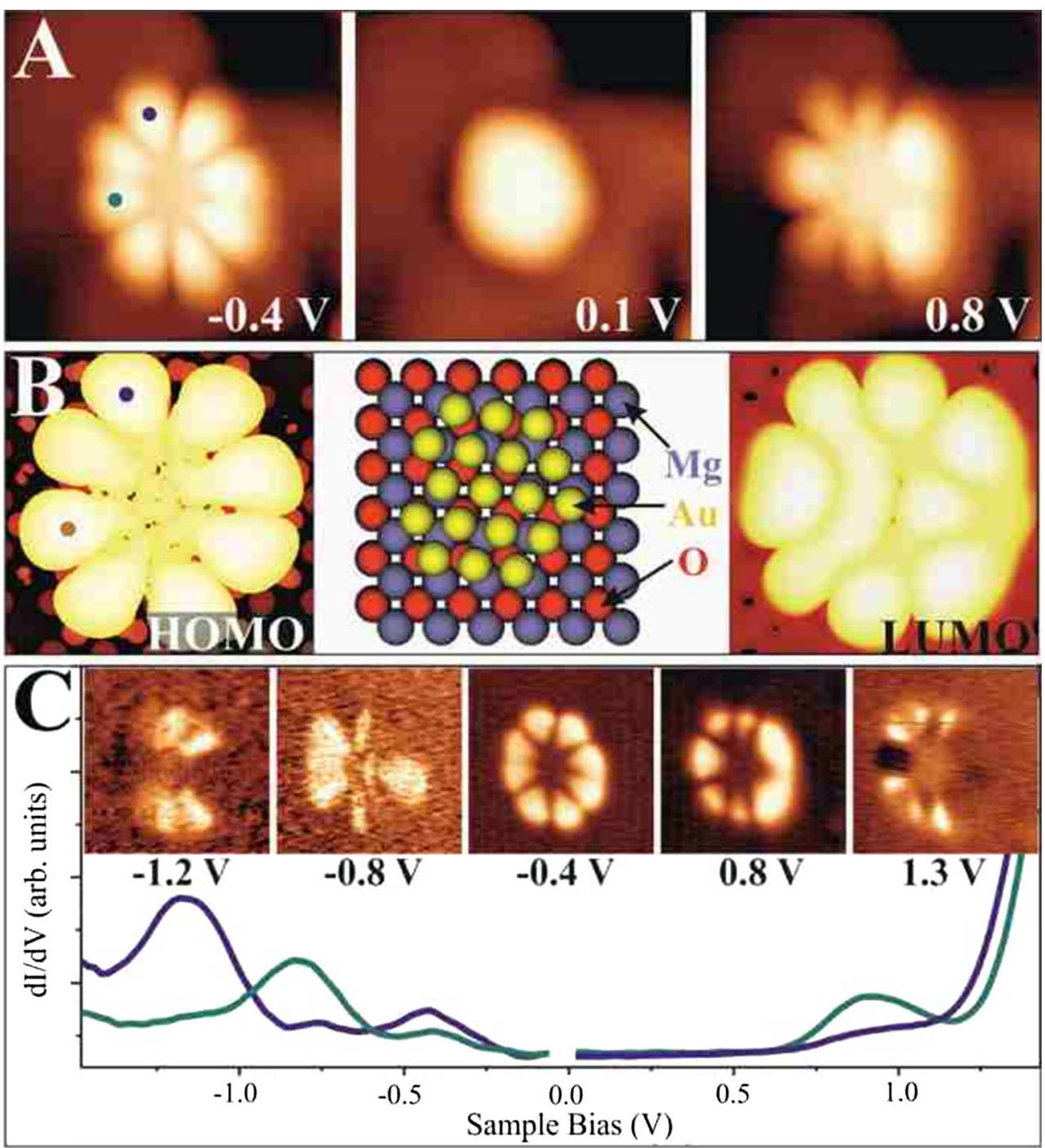

to the delocalized quantum well states, there is a difference of four electrons to the total electron count. The missing electrons are introduced via charge transfer from the $\mathrm{MgO} /$ $\mathrm{Ag}$ interface into the $\mathrm{Au}$ island. This charging effect is corroborated by a DFT Bader analysis, yielding a value of -3.54lel for the $\mathrm{Au}_{18}$ cluster, but matches also the average transfer of -0.2 lel per atom as calculated for dense-packed $\mathrm{Au}$ layers on thin $\mathrm{MgO}$ films [56]. Similar procedures have been carried out for many other $\mathrm{Au}$ aggregates on the $\mathrm{MgO}-\mathrm{Ag}(001)$ system [56]. In all cases, a negative charging has been revealed, verifying the charge-mediated binding concept for $\mathrm{Au}$ islands on thin oxide films [59-61].

Another example is electron transfer from the $\mathrm{NiAl}$ metal substrate through a thin alumina film into Au chains formed on its surface [62]. Formation of an $\mathrm{Au}-\mathrm{Al}$ bond involves breaking of an oxide $\mathrm{Al}-\mathrm{O}$ bond below the adatom and at the same time forming a new bond between the hence under-coordinated $\mathrm{O}$ ion to an $\mathrm{Al}$ atom in the $\mathrm{NiAl}$.
Combining low temperature STM with DFT, it was possible to count the number of electrons transferred by analysing the nodal structure of the highest occupied orbitals.

The concept of charge-mediated control of the metaloxide adhesion is not restricted to ultrathin films but other electron sources may be explored. One possibility to extend the concept of charge-mediated particle growth to bulk oxides is the insertion of suitable charge sources directly into the oxide material, preferentially into a near-surface region to allow for charge exchange with adsorbates. The fundamental approach to insert charge centers into a material is doping, and the underlying concepts have been introduced and brought to perfection already in the mature field of semiconductor technology. Oxides are subject to self-doping either by native defects or by unwanted impurities, the concentration of which is difficult to control experimentally [63]. Both lattice defects and impurity ions may adopt different charge states in the oxide lattice [64, 

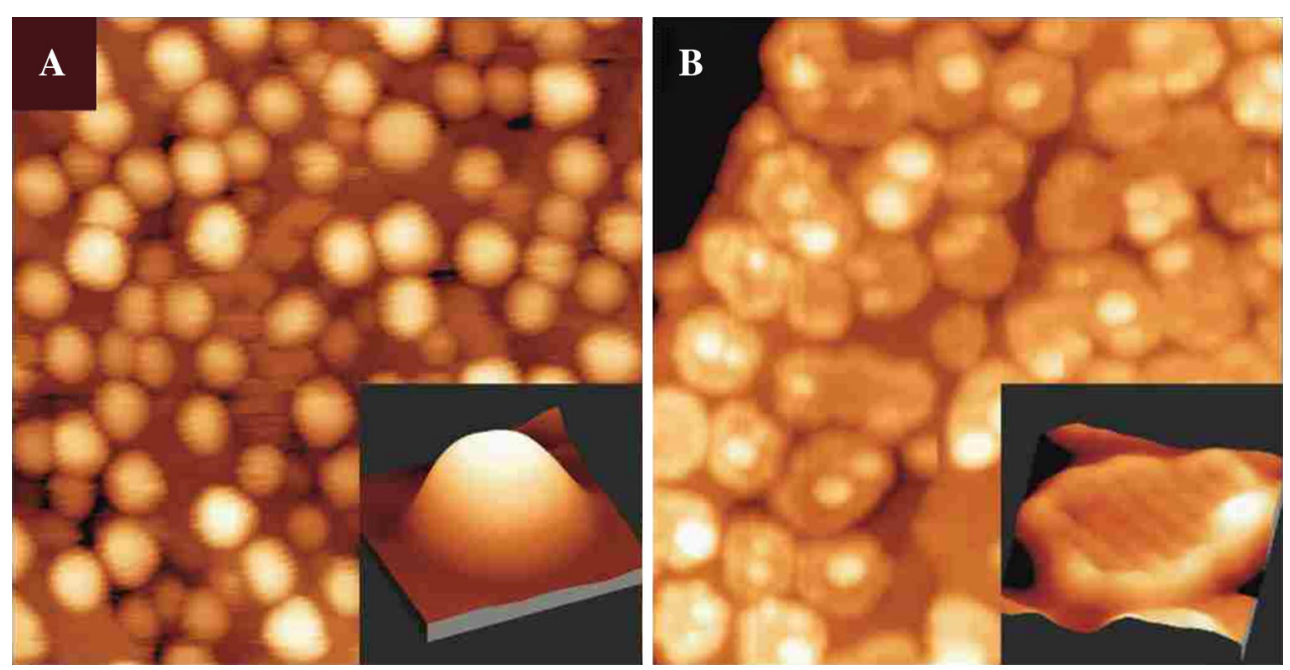

Fig. 8 STM images of $0.7 \mathrm{~mL}$ Au dosed onto a pristine and $\mathbf{b}$ doped $\mathrm{CaO}$ films $\left(4.5 \mathrm{~V}, 50 \times 50 \mathrm{~nm}^{2}\right)$. The insets display close-ups of two characteristic particles $\left(-5.0 \mathrm{~V}, 10 \times 10 \mathrm{~nm}^{2}\right)$

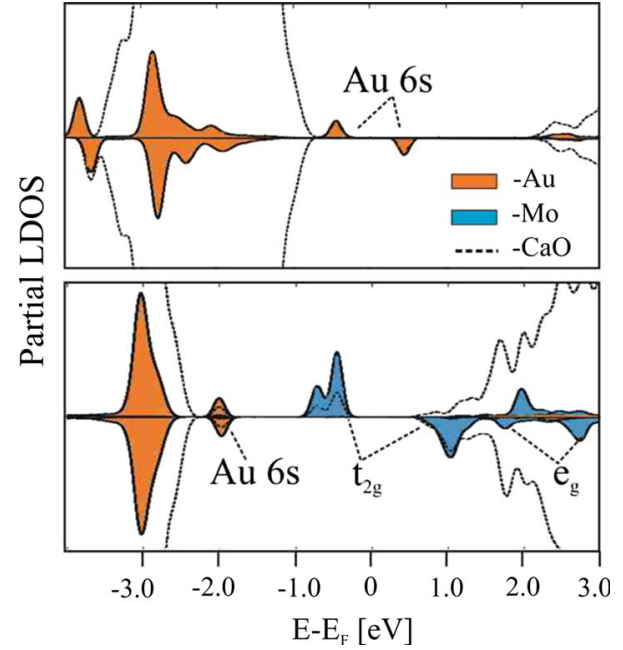

Fig. 9 PBE projected state-density calculated for non-doped (top) and doped (bottom) $\mathrm{CaO}$ films in presence of an $\mathrm{Au}$ adatom [66]

65], a variability that leads to pronounced compensation effects. Finally, the dopants may be electrically inactive in a wide-gap insulator, as thermal excitation is insufficient to promote electrons from defect states into bulk bands. As a result, the excess charges remain trapped at the host ions. Whereas high-valence dopants may serve as charge donors and provide extra electrons, undervalent dopants have acceptor character and may accommodate electrons from suitable adsorbates. Based on the above considerations it is now expected that charge donors in an oxide lattice have a similar influence on the particle shape as the metal support below a thin oxide film.

The impact of doping on the growth morphology of gold has first been realized for crystalline $\mathrm{CaO}(001)$ doped with
Mo in the sub-percent range [66]. On the doped oxide, gold was found to spread out into extended monolayer islands, while the conventional 3D growth regime prevailed on pristine, non-doped material (Fig. 8). Evidently, the donor character of the Mo dopants is responsible for the 2D growth morphology, as the bare $\mathrm{CaO}(001)$ surface interacts with gold only weakly.

The Mo-impurity ions mainly occupy Ca substitutional sites and, in the absence of gold, adopt the typical $2+$ charge state of the rock salt lattice in order to maintain charge neutrality. In the $2+$ configuration, four Mo $4 \mathrm{~d}$ electrons are localized in the dopant, three of them occupying $\left(t_{2 g}-a\right)$ crystal field states and one sitting in a $\left(t_{2 g}-b\right)$ level close to the upper end of the $\mathrm{CaO}$ band gap (Fig. 9) [66].

Especially, the latter one is in an energetically unfavorable position and therefore susceptible to be transferred into an acceptor state with lower energy. Such acceptor states are provided by $\mathrm{Au}$ atoms, which expose half-filled $\mathrm{Au}$ 6s levels at lower energy. DFT calculations revealed a spontaneous transfer of the topmost Mo 4d-electron into the Au 6s affinity level, resulting in the formation of an $\mathrm{Au}^{-}$-anion (Fig. 9). We emphasize that the charge transfer does not require the presence of a Mo ion in the surface but remains active over relatively large Mo-Au distances of up to ten atomic planes.

The increase of the metal-oxide adhesion due to dopantinduced charge transfer fully explains the 2D growth regime of gold observed in the experiment. Gold tends to wet the $\mathrm{CaO}$ surface in an attempt to maximize the number of exchanged electrons, hence the interfacial interaction. Further DFT calculations suggested that also a $\mathrm{Mo}^{3+}$ species that has already lost one electron remains a potential donor, as two of the residual d-electrons are still higher in 
energy than the Au 6s affinity level [67]. Consequently, even a second and third electron may be transferred into the ad-metal, leaving behind thermodynamically stable $\mathrm{Mo}^{4+}$ and $\mathrm{Mo}^{5+}$ ions in the $\mathrm{CaO}$ lattice. It is this behavior of the Mo ions that is responsible for the robust donor behavior of Mo-doped $\mathrm{CaO}$ [66]. The presence of suitable dopants is, however, not the only requirement for a stable donor characteristic, but also the interplay between dopants and host oxide determines the redox activity. One conclusion from detailed studies on Mo dopants is that the donor behavior of a transition-metal-doped oxide cannot be predicted by simple valence arguments but needs to be checked in every single case.

The influence of overvalent dopants on the equilibrium morphology of metal particles can, to a certain extent, be annihilated by undervalent dopants in the oxide lattice [68, 69]. Dopants with lower charge state generate holes in the oxide electronic structure that are able to trap the extra electrons provided by the charge donors. This mutual compensation between donors and acceptors has been explored for $\mathrm{CaO}$ films co-doped with $\mathrm{Li}$ and $\mathrm{Mo}$ ions [70]. As a result, charge transfer to the surface ceases at a critical Li doping level and the Au deposits adopt the typical 3D geometry of pristine $\mathrm{CaO}$ films.

Gold forms monolayer islands if deposited onto a Modoped $\mathrm{CaO}$ under vacuum conditions, but $3 \mathrm{D}$ particles if oxygen is present during growth. The reason is that $\mathrm{O}_{2}$ molecules bound to the surface act as electron acceptors and trap charges in their $\mathrm{O} 2 \mathrm{p}^{*}$ antibonding orbitals. These electrons are lost for the $\mathrm{Au}$ islands, resulting in a gradual transition from a $2 \mathrm{D}$ to a $3 \mathrm{D}$ growth regime with increasing $\mathrm{O}_{2}$ partial pressure. Whereas in $5 \times 10^{-7}$ mbar of oxygen, $50 \%$ of the Au islands still adapt monolayer shapes, all $\mathrm{Au}$ deposits turn 3D when grown in a $5 \times 10^{-5} \mathrm{mbar}^{\mathrm{O}_{2}}$ background. The interplay between the observed growth mode and the composition of the gas environment emphasizes the pivotal importance of excess electrons from donor species for the reactivity of oxides towards adsorption of metallic and gaseous species.

This observation also opens up other options to control surface reactivity. One is to use dopants to activate oxygen to participate in oxidative methane coupling a reaction of potential for applications [15].

Using scanning tunneling microscopy and density functional theory, evidence is provided that strongly bound $\mathrm{O}_{2}{ }^{-}$species with high susceptibility for dissociation form even on chemically inert $\mathrm{CaO}(001)$ after it has been doped with Mo ions. Figure 10 displays STM images of such a doped $\mathrm{CaO}(001)$ film before and after exposure to $\mathrm{O}_{2}$ [71].

In empty-state images, the adsorbates appear as circular depressions $0.6 \AA$ in depth and $10 \AA$ in diameter (Fig. 10f). Exposing them to electrons from the STM tip reveals their molecular nature, as they split into pairs of identical minima that are assigned to the respective $\mathrm{O}$ atoms (Fig. 10d, e) [72].

The bond cleavage occurs as a second electron enters the anti-bonding states of the already weakened superoxo species. Whereas a mean $\mathrm{O}-\mathrm{O}$ distance of $10-15 \AA$ is observed directly after dissociation, this number increases with time due to a repulsive character of the $\mathrm{O}-\mathrm{O}$ interaction on the surface. The two types of oxygen species can be distinguished also in bias-dependent topographic images. While the molecules show pronounced negative contrast, the atomic species appear fainter and are surrounded by a bright halo (Fig. 10e).

The adsorption efficiency of oxygen strongly depends on the preparation of the $\mathrm{CaO}$ films, in particular on the concentration of the Mo dopants. Whereas Mo-poor films are unable to bind oxygen, a rather high adsorbate concentration is found for Mo-rich preparations, indicating the crucial role of the dopants in binding $\mathrm{O}_{2}$. Dopants and $\mathrm{O}_{2}$ molecules are expected to interact directly with each other. Experimental evidence comes from $\mathrm{O}$ desorption experiments, in which isolated molecules are removed from the surface by a bias pulse with the tip. In $50 \%$ of these experiments, a Mo donor is detected below the molecule. Interestingly, the dopant never occupies a position directly in the top layer but sits in sub-surface oxide planes, as deduced from the diameter of characteristic charging rings emerging in the STM images [73]. It is concluded that the Mo ions are able to exchange charges with the surface $\mathrm{O}_{2}$ molecules even over distances as large as $1 \mathrm{~nm}$, most likely via electron tunneling. The electron transfer between Mo donors and $\mathrm{O}_{2}$ acceptors has been investigated with DFT calculations performed at the $\mathrm{B} 3 \mathrm{LYP}+\mathrm{D}$ level. On non-doped $\mathrm{CaO}(001)$, a neutral $\mathrm{O}_{2}$ molecule binds with $13 \mathrm{~kJ} / \mathrm{mol}$ (mostly from dispersion forces) to a $\mathrm{Ca}-\mathrm{Ca}$ bridge position, while $\mathrm{Ca}^{2+}$ top sites are less preferred. In contrast, an $\mathrm{O}_{2}{ }^{-}$species binds to the same bridge site with a binding energy of $87 \mathrm{~kJ} / \mathrm{mol}$ when a $\mathrm{Mo}^{3+}$ ion is present in the third subsurface plane. The charge transfer to oxygen becomes even more favorable for $\mathrm{Mo}^{2+}$ donors in the oxide film, given their low ionization energy [66]. Further evidence for the formation of superoxo species comes from the calculated bond elongation (121-133 pm) and the reduced stretching frequency $\left(1,537-1,200 \mathrm{~cm}^{-1}\right)$ computed for $\mathrm{O}_{2}$ molecules on the doped oxide. Moreover, the total spin of the system decreases from $5 / 2\left(3 / 2\right.$ for $\mathrm{Mo}^{3+}$ (d3) plus 1 for $\mathrm{O}_{2}$ ) to $3 / 2\left(1\right.$ for $\mathrm{Mo}^{4+}$ (d2) plus $1 / 2$ for $\left.\mathrm{O}_{2}{ }^{-}\right)$in response to the charge transfer. And finally, the lower apparent dissociation barrier for super-oxo species on doped $\mathrm{CaO}(66 \mathrm{~kJ} / \mathrm{mol})$ compared to that of neutral $\mathrm{O}_{2}$ on pristine $\mathrm{CaO}(110 \mathrm{~kJ} / \mathrm{mol})$ has been calculated, following the trend observed experimentally. It is concluded that dopants may play a pivotal role in the activation of hydrocarbons on wideband-gap oxides. Given the activated oxygen one might easily envision its participation in hydrocarbon activation, in 
Fig. 10 Top panel STM images of a pristine $25 \mathrm{~mL} \mathrm{CaO}(001)$ film $\left(4.0 \mathrm{~V}, 80 \times 80 \mathrm{~nm}^{2}\right)$ and b films after $\mathrm{O}_{2}$ exposure of $5 \mathrm{~L}$ at $20 \mathrm{~K}$ and c $200 \mathrm{~L}$ at $300 \mathrm{~K}$ $\left(40 \times 40 \mathrm{~nm}^{2}\right)$. Lower panel: STM images of the same $\mathrm{O}_{2-}$ covered region of Mo-doped $\mathrm{CaO}$ taken $\mathbf{a}$ before and $\mathbf{b}$ after multiple scans at $4.0 \mathrm{~V}(3.3 \mathrm{~V}$, $40 \times 40 \mathrm{~nm}^{2}$ ). Note the dissociation of most molecules into atom pairs upon electron injection from the tip. $\mathbf{c}$ Height profile and bias-dependent contrast of oxygen molecules and atoms. While atoms appear with pronounced sombrero shapes at higher bias, the molecules are imaged as deep depressions in the surface [71]
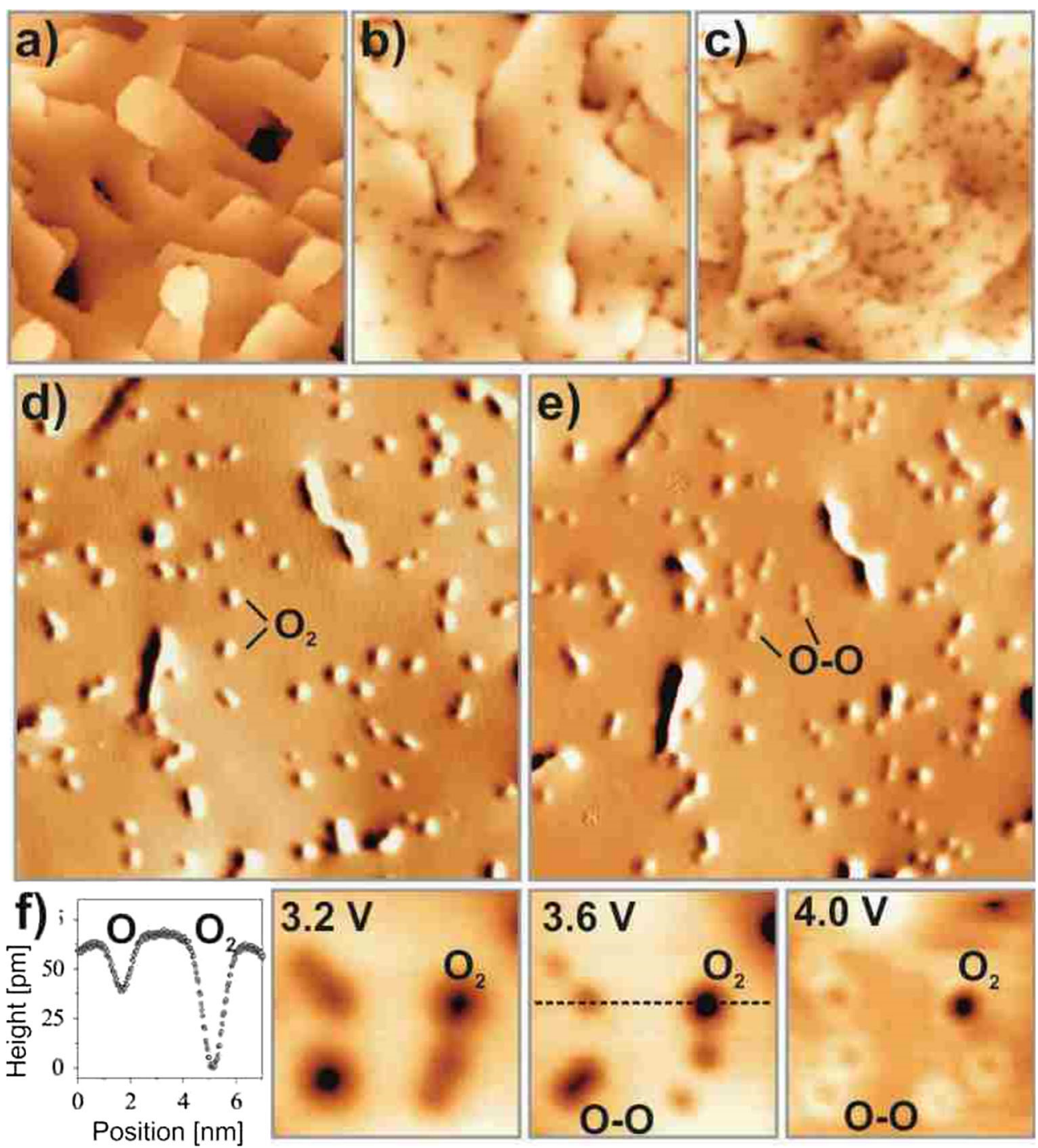

fact, the latter has been confirmed in a study by Schlögl's group, who investigated the reaction yield for the oxidative coupling of methane over Fe-doped $\mathrm{MgO}$ powder [74].

\subsection{Example \#3: Olefin Hydrogenation: Nanoparticles Versus Single Crystals}

Industrially used catalysts often require small amounts of additives, such as halogens or alkali metals, to ensure high catalytic activity and selectivity [1]. One of the most important modifiers for surface processes involving transformation of hydrocarbons is carbon, which is formed as a decomposition product at early stages of a reaction. It has been recognized for a long time that accumulation of dehydrogenated carbonaceous deposits affect the activity and selectivity of hydrocarbon conversions with hydrogen on transition metals [75-77]. While for a long time carbon was considered a site blocker, Geoff Webb [78] suggested that it is the hydrogen directly connected with the carbon is the relevant species involved in hydrogenation. The traditional opinion that only surface hydrogen species participate in the hydrogenation process was also questioned by Ceyer and co-workers studying ethylene hydrogenation on $\mathrm{Ni}(111)$ [79]. More recently, other experimental and theoretical evidences for the important role of subsurface hydrogen were reported and it has been suggested that the carbonaceous species control the hydrogen distribution on and in the particle [80-82].

The existence of different hydrogen species in and on the nanoparticles may potentially result in some important implications for the overall activity and selectivity of the hydrogenation catalyst: if one of the key reaction stepsthe formation of subsurface hydrogen, which is known to be a structure sensitive process-is slow under reaction 
conditions, the hydrogen permeability of the metal surface may be decisive for hydrogenation activity.

In recent studies the hydrogenation activity of a $\operatorname{Pd}(111)$ single crystal surface and Pd nanoparticles supported on $\mathrm{Fe}_{3} \mathrm{O}_{4} / \mathrm{Pt}(111)$ model catalyst was investigated using a combination of isothermal pulsed molecular beam (MB) methods and resonant nuclear reaction analysis for hydrogen depth profiling (r-NRA) to further clarify the microscopic mechanisms active for hydrogenation over $\mathrm{Pd}$ catalysts [83-87].

This permitted to address the question of how does the activity and selectivity of competing reaction pathways in olefin conversions with hydrogen depend on the structure of the metal nanoclusters, and on the presence of surface modifiers such as e.g. carbon.

It was found that: (i) hydrogenation of the olefinic double bond requires the presence of subsurface hydrogen, and a particular reaction step-the second half-hydrogenation (see the scheme below) - was identified as linked to the availability of sub-surface hydrogen species; (ii) sustained hydrogenation can be achieved on Pd nanoparticles only when low-coordinated surface sites (edges, corners) were modified by adsorbed carbon or carbonaceous species. Neither C-free Pd nanoparticles nor C-free or C-modified $\operatorname{Pd}(111)$ surfaces were found to be capable of maintaining hydrogenation activity under steady state conditions; (iii) carbonaceous deposits influence the reactivity by a pronounced facilitation of hydrogen diffusion into the subsurface of Pd nanoparticles through C-modified low-coordinated surface sites.

Olefin conversions with $\mathrm{H}_{2}$ are described by the HoriutiPolanyi mechanism, which proceeds through a series steps [88]. Specifically for cis-2-butene the molecule used in this model study a first half-hydrogenation step forms a surface butyl species, which is an intermediate for both a cis-trans isomerization, which leads to the desorption of transbutene and if performed using $\mathrm{D}_{2}$ to trans-2-butene-d1 and as full hydrogenation to butane-d2. Dehydrogenation of the adsorbed alkene to other carbonaceous surface species is also possible, giving rise to the accumulation of dehydrogenated hydrocarbon species. Two independent molecular beams were used to dose the reactants-cis-2-butene and $\mathrm{D}_{2}$ - with the evolution of gas phase products under isothermal conditions, monitored as a function of time by quadrupole mass spectrometry. As a model catalyst, Pd nano-particles supported on a thin, planar $\mathrm{Fe}_{3} \mathrm{O}_{4}(111)$ film were prepared under UHV conditions. The Pd nanoparticles are on average $6 \mathrm{~nm}$ in diameter and exhibit mainly (111) facets (abundance $80 \%$ ) and a smaller fraction of (100) facets and other low-coordinated surface sites such as edges and corners (abundance $20 \%$ ). IR-spectroscopy of $\mathrm{CO}$ probe molecules adsorption has been used to show that sub-monolayer amounts of $\mathrm{C}$ are produced on the $\mathrm{Pd}$ nanoparticles, which selectively block the low-coordinated surface sites while leaving the majority of the regular (111) facets C-free. Both types of catalysts-C-free and $\mathrm{C}$-modified (with the edges and corners covered by $\mathrm{C}$ ) were used to compare their catalytic activities and selectivities with regard to the competing hydrogenation and cis-trans isomerization pathways.

Hydrogenation rates of cis-2-butene over clean and $\mathrm{C}$-containing surfaces of Pd nanoparticles supported on the $\mathrm{Fe}_{3} \mathrm{O}_{4}(111) / \mathrm{Pt}(111)$ oxide film are shown in Fig. 11a. On the initially clean particles, both reaction pathways exhibit a short induction period followed by a transient period of high activity. However, for C-free nanoparticles at $260 \mathrm{~K}$, only, cis-trans isomerization activity is sustained over extended periods of time, whereas the hydrogenation rate quickly decreases and returns to zero on carbon free nanoparticles. Remarkably, not only isomerization but also hydrogenation is maintained under steady state conditions on the catalyst that was $\mathrm{C}$-modified prior to reaction (Fig. 11b). This unique catalytic behavior clearly demonstrates the promoting role of $\mathrm{C}$ in the persistent hydrogenation activity of the Pd catalyst [83].

More detailed studies revealed that two different hydrogen species must be involved. The hypothesis was established that those two species are surface and subsurface hydrogen. Measurements of the concentrations of surface and subsurface $\mathrm{H}$ species by NRA for hydrogen depth profiling and complementary transient molecular beam experiments were combined to measure the reaction rates $[83,91]$. The former method (described in detail in Ref. [91]) was used to independently monitor the concentrations of the surface-adsorbed and subsurface (or volumeabsorbed) $\mathrm{H}$ species as a function of hydrogen pressure in the environment (Fig. 12).

Upon inspection, it is obvious that due to the higher binding energy of surface hydrogen, the surface saturates at a hydrogen pressure below $10^{-6}$ mbar via a non-activated molecular hydrogen dissociation process. The sub-surface hydrogen, on the other hand, shows a pronounced pressure dependence between $10^{-7}$ and $2 \times 10^{-5} \mathrm{mbar}$, indicative of the activated step of hydrogen penetration through the surface layer. Via molecular beam experiments at two different pressure conditions, where the surface hydrogen concentration was in saturation but the sub-surface hydrogen concentration varied considerably, it was demonstrated that the full hydrogenation step of cis-butene required the presence of sub-surface hydrogen, while the cis-trans-isomeraization was independent of it.

Having established the nature of the H(D) atoms involved in hydrogenation, one can now explain the observations displayed in Fig. 13. On the initially clean nanoparticles pre-saturated with $\mathrm{D}_{2}$ prior to olefin exposure, both surface and subsurface D species are populated, 
Fig. 11 Results from isothermal pulsed molecular beam experiments on the conversion of cis-2-butene with $\mathrm{D} 2$ at $260 \mathrm{~K}$ on a initially clean and b C-modified $\mathrm{Pd} / \mathrm{Fe}_{3} \mathrm{O}_{4} /$ $\mathrm{Pt}(111)$ model catalysts. Shown is the evolution of the reaction rates as a function of time for trans-2-butene-d1 (black curves) and butane-d 2 (grey curves). The catalysts were exposed to D2 beam continuously, the cis-2-butene beam was pulsed (from [89]). At the top scanning tunneling micrographs showing Pd nanoparticles supported on a model alumina film in two different magnifications [90]

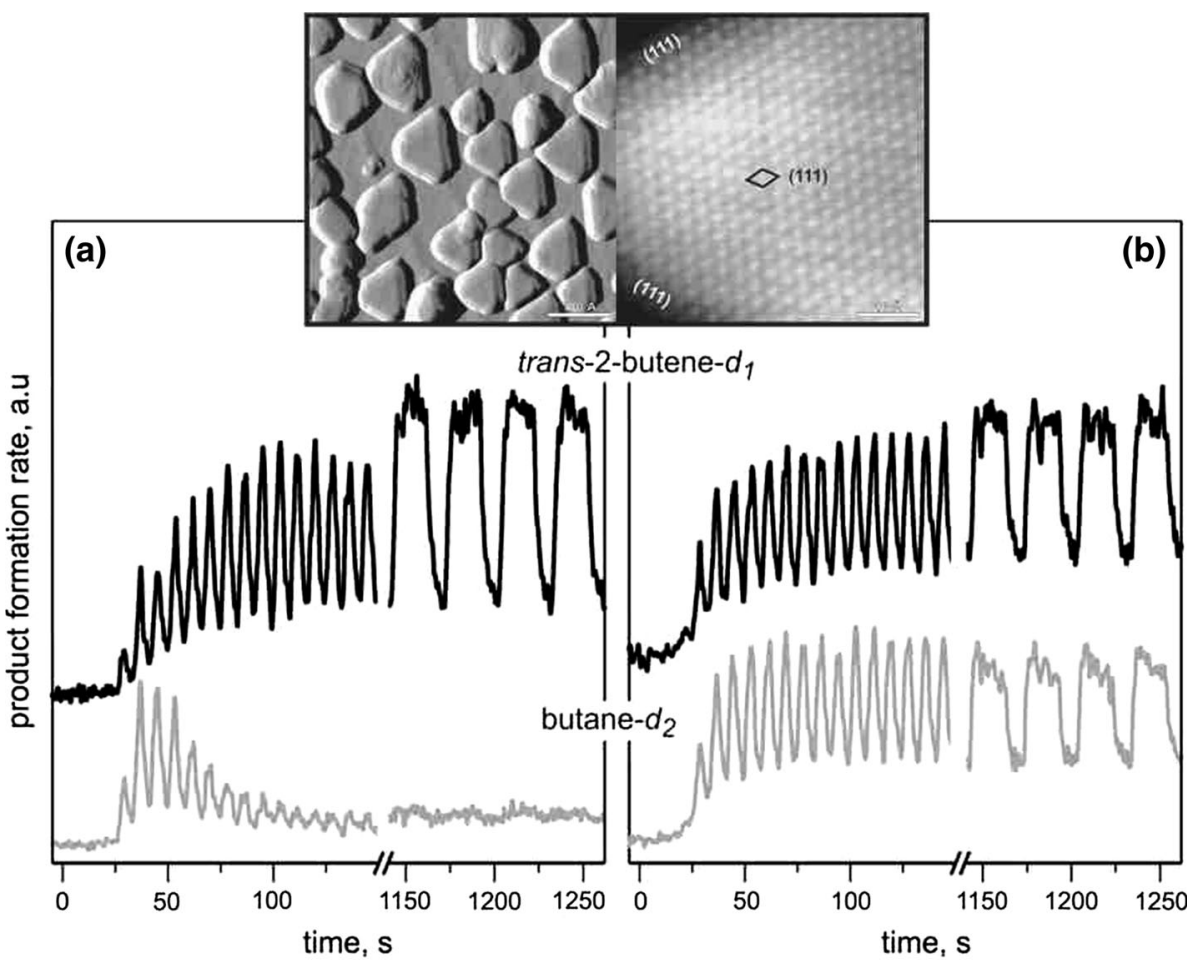

clean Pd nanoparticles
Pd nanoparticles with carbon adsorbed at low-coordinated sites
Fig. 12 Grazing-incidence NRA yield curves of $\mathrm{H}$ in $\mathrm{Al}_{2} \mathrm{O}_{3}$-supported $\mathrm{Pd}$ nanoparticles at various $\mathrm{H}_{2}$ pressures at $94 \mathrm{~K}$. The inset shows $\mathrm{H}_{2}$-pressure dependence of surface-adsorbed and clusterabsorbed H (from [83])

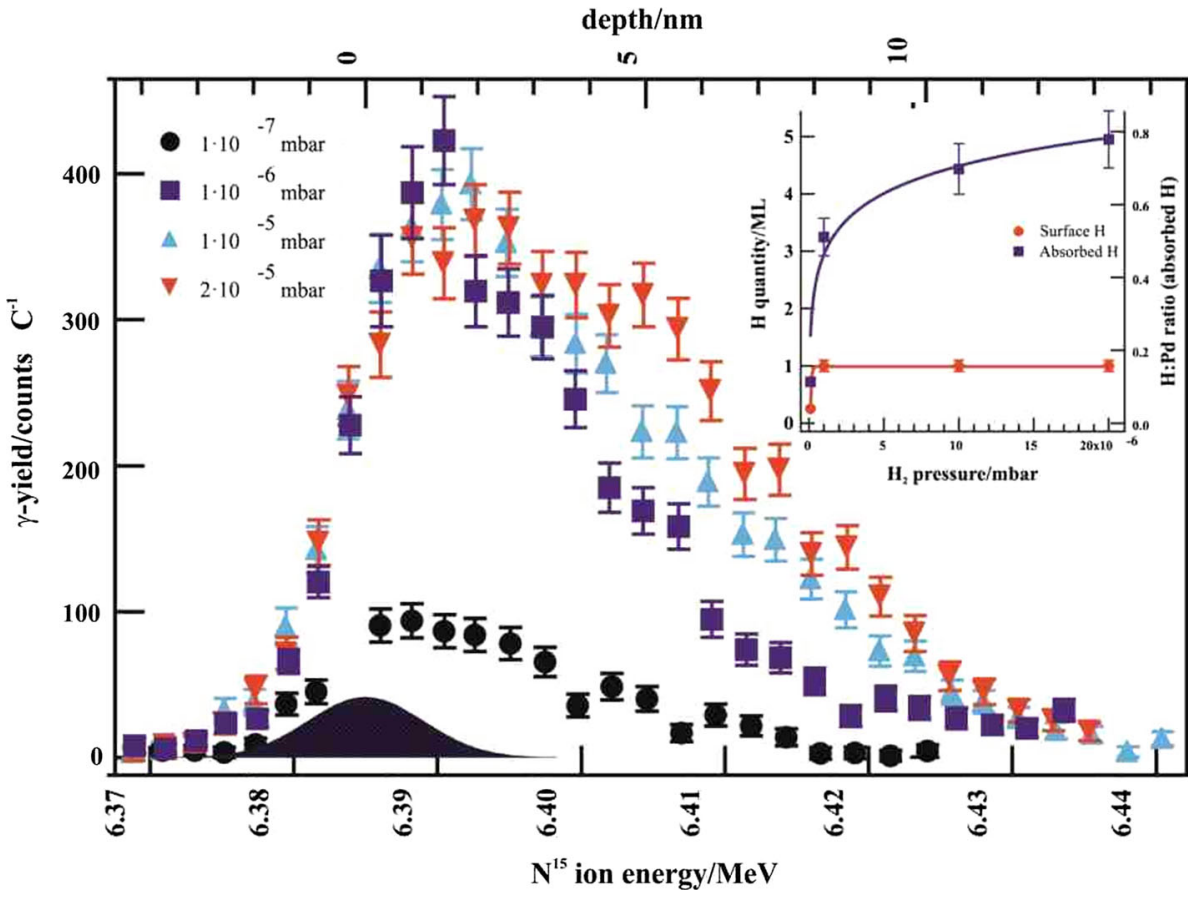

which results in high initial hydrogenation rates. After prolonged olefin exposure, hydrogenation becomes suppressed most likely because of the depletion of the subsurface D reservoir, which cannot be effectively replenished under the steady state reaction conditions. The inability to populate subsurface D arises from hindered D subsurface diffusion under steady state reaction conditions through the surface. Since sustained hydrogenation occurs 


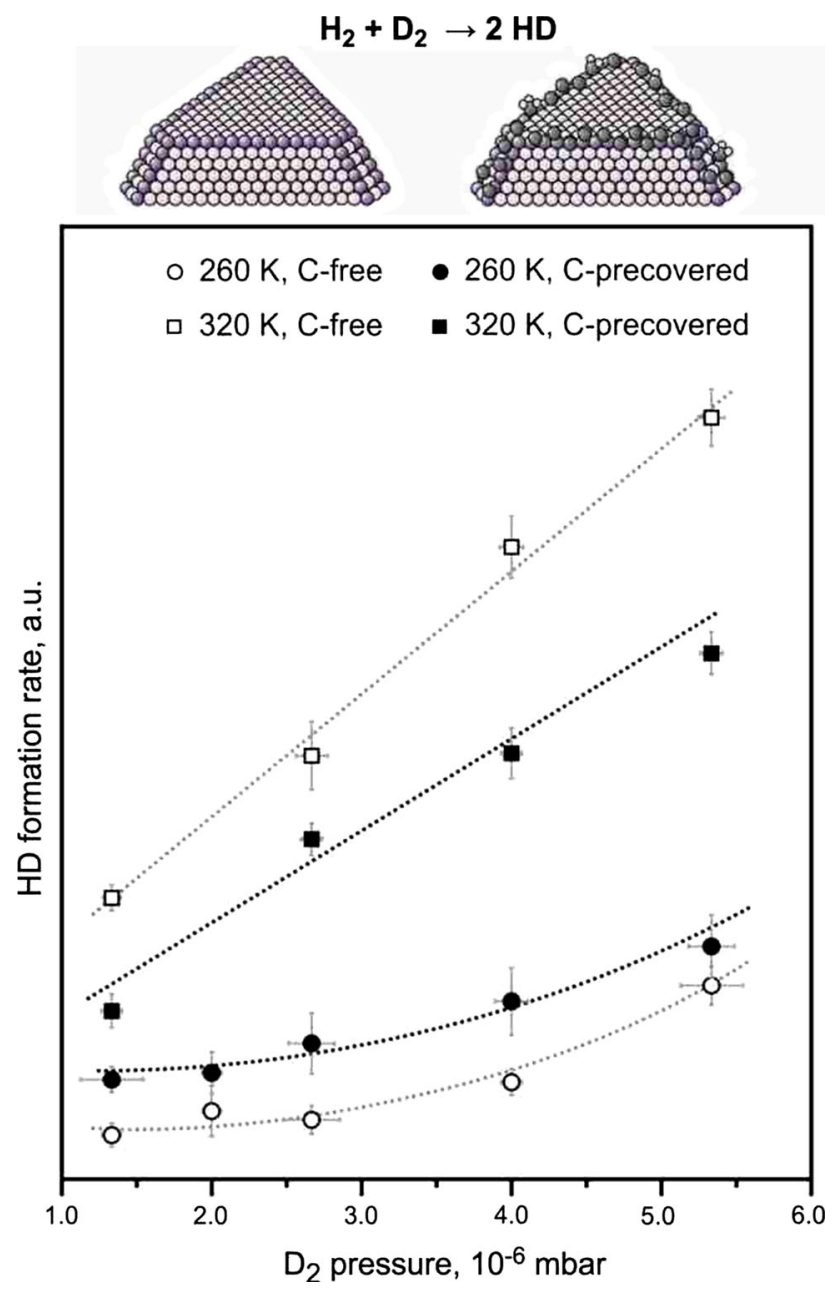

Fig. 13 The steady state HD formation rates obtained on the pristine and C-precovered $\mathrm{Pd}$ nanoparticles supported on $\mathrm{Fe}_{3} \mathrm{O}_{4} / \mathrm{Pt}(111)$ at 260 and $320 \mathrm{~K}$ in the $\mathrm{D}_{2}$ pressure range from $1.3 \times 10^{-6}$ to $5.3 \times 10^{-6}$. mbar. The reactant ratio $\mathrm{D}_{2}: \mathrm{H}_{2}$ was kept constant at 71 . C deposition result in the $\sim 30 \%$ decrease of the HD formation rate at $320 \mathrm{~K}$ and in $\sim 100 \%$ increase of the reaction rate at $260 \mathrm{~K}$. At the top of Fig. 10 and carbon decorated nanoparticles are shown schematically (from [87])

on Pd nanoparticles modified with carbon, it can be concluded that for this system subsurface D can be effectively replenished on the time scale of our kinetic experiments.

In further studies on $\mathrm{H}_{2}+\mathrm{D}_{2} \Rightarrow 2 \mathrm{HD}$ exchange reactions direct experimental evidence for a faster subsurface $\mathrm{H}$ diffusion through C-modified low-coordinated surface sites on Pd nanoparticles [87].

The microscopic origin of the proposed $\mathrm{C}$-assisted subsurface $\mathrm{H}$ diffusion was revealed by computing for model particles (in collaboration with K. Neyman) the activation barriers for hydrogen diffusion into the volume of Pd nanoparticles on C-free and C-containing surfaces [85]. It was shown that deposited carbon dramatically enhances the hydrogen diffusion rate into the subsurface region of Pd nanoparticles, mainly due to local elongation of Pd-Pd bonds, which results in a lowering of the activation barrier for subsurface hydrogen diffusion. In contrast, the lateral rigidity of the extended $\operatorname{Pd}(111)$ surface was predicted to hinder this effect and does not allow facilitation of subsurface $\mathrm{H}$ diffusion by deposited $\mathrm{C}$ atoms. This result demonstrates the conceptual importance of atomic flexibility of sites near nanoparticle edges that, in contrast to the intrinsically rigid regular single crystal surfaces, play a crucial role in subsurface hydrogen diffusion on Pd.

The steady state $\mathrm{HD}$ formation rates obtained during $\mathrm{D}_{2}$ and $\mathrm{H}_{2}$ exposure for reaction temperatures of 260 and $320 \mathrm{~K}$ on clean and C-modified Pd nanoparticles using a range of pressure conditions with a constant $\mathrm{D}_{2}: \mathrm{H}_{2}$ ratio are shown in Fig. 10. Whereas at $320 \mathrm{~K}$ pre-adsorbed $\mathrm{C}$ reduces the overall reaction rate by about $30 \%$, the reaction rate increases by about $100 \%$ at $260 \mathrm{~K}$ on the $\mathrm{C}$-modified nanoparticles for all pressures studied. The decreased $\mathrm{HD}$ formation rate in the high-temperature regime, where HD formation is dominated by the recombination of the surface $\mathrm{H}$ and $\mathrm{D}$ species is due to the blocking of surface adsorption sites by $\mathrm{C}$. The increase in HD formation rate in the low-temperature regime, where desorption involves at least one subsurface $H(D)$ species can be explained only by the higher formation rate of the sub-surface $\mathrm{H}(\mathrm{D})$ species on the C-modified nanoparticles resulting in a higher steady state concentration of subsurface hydrogen species. At the microscopic level the facilitation of subsurface $\mathrm{H}$ diffusion through $\mathrm{C}$-modified lowcoordinated sites is most likely even more pronounced, since the nearly $100 \%$ increase of the overall reaction rate arises from modification of only $20 \%$ of the surface sites constituting edges and corners of Pd nanoparticles. In summary, the molecular beam experiments on olefin conversions with hydrogen over well-defined Pd nanoparticles supported on $\mathrm{Fe}_{3} \mathrm{O}_{4} / \mathrm{Pt}(111)$ oxide films and $\mathrm{Pd}(111)$ allowed us to obtain a comprehensive microscopic picture of hydrogenation and isomerization processes on the nanostructured catalysts.

Coming back to the statement at the outset of this case study, we note that based on model studies, where we systematically increase the complexity from metal single crystals to clean oxide supported metal particles, which are modified by carbon or carbonaceous species deposition in strategically relevant sites, it is possible to unravel the detailed interplay of components of the system-It is, finally, the combination of the structural flexibility of a nano-particle with the strong binding of the carbon modifier on particles edges and corners that controls hydrogen population at the surface and thus guaranties the sustained catalytic activity of the system as a function of temperature by influencing hydrogen diffusion between the surface and sub-surface. It is hard to envision how one could have 
reached detailed atomic insight of this nature without relying on model systems with increasing degree of complexity.

\section{Summary and Outlook}

We have discussed a number of case studies in order to show how a model studies approach may be linked to the investigation of real catalytic material and catalytic reactions. The advantage of the model study approach is the possibility to identify factors that determine the properties of catalytic materials with respect to reactions by systematically increasing the complexity of the system. With this approach we are now in the position to answer well-defined questions by capturing specific aspects that are thought to be of important for particular materials and reactions. We have done this by choosing case studies that address some of those well-defined questions and have tried to relate this to real catalysis. The approach has led us to certain points, indicated in the schematic diagram shown in Fig. 1 by combining both theory and experiment. This was only possible because, both, in theory and experiment the scientific community has made considerable progress in advancing the ability to address, by computational techniques systems of relevant size, as well as by developing novel experimental approaches that may be applied to the study of surfaces under ultrahigh-vacuum and ambient conditions. The development has, by far, not reached a point where we may address the relevant questions of structure-relationships under operating conditions. In fact, further, increasing efforts have to be made to develop the field further in this direction. It has been impossible, in this short review to cover all innovative developments, in particular with respect to in situ experimental studies, where a lot of innovative approaches have been launched recently, including ambient pressure X-ray photoelectron spectroscopy [92], non-linear optical spectroscopy [93], ambient pressure scanning tunneling microscopy [94], in situ transmission electron microscopy with Cs correction [95] and many more, but we have rather chosen here to address the development of model systems that move towards capturing structural and functional features of real catalysts, which then in the future may be addressed with this increasing toolbox of new techniques, which are under rapid development at present.

Acknowledgments We would like to thank our coworkers, who are mentioned in the references for their important contributions to the work described. HJF also thanks Gianfranco Pacchioni and Hannu Häkkinen for decisive contributions to the results discussed in case study \#2. We are grateful to the funding agencies that have provided financial support, i.e. German Science Foundation (DFG), Alexander von Humboldt Foundation $(\mathrm{AvH})$, Fonds der Chemischen Industrie
(FCI), as well as the institutions we are members of, i.e. Humboldt Universität zu Berlin and Max-Planck Gesellschaft.

\section{References}

1. Ertl G, Knözinger H, Weitkamp J (1997) Handbook of heterogeneous catalysis. $\mathrm{VCH}$, Weinheim

2. Ertl G, Freund H-J (1999) Catalysis and surface science. Phys Today 52(1):32-38

3. Ostwald W (1923) Über Katalyse. Akademische Verlagsgesellschaft, Leipzig

4. Marin G, Yablonsky GS (2011) Kinetics of chemical reactions. Wiley-VCH Verlag GmbH \& Co. KGaA, Weinheim

5. Freund HJ (2010) Model studies in heterogeneous catalysis. Chem Eur J 16(31):9384-9397. doi:10.1002/chem.201001724

6. Freund HJ, Nilius N, Risse T, Schauermann S (2014) A fresh look at an old nano-technology: catalysis. Phys Chem Chem Phys 16(18):8148-8167. doi:10.1039/C3CP55231D

7. Freund H-J, Nilius N, Risse T, Schauermann S, Schmidt T (2011) Innovative measurement techniques in surface science. ChemPhysChem 12(1):79-87. doi:10.1002/cphc.201000812

8. Böhme DK, Schwarz H (2005) The ultimate single site catalysis. Angew Chem Int Ed 44:2336

9. Ertl G (2007) Reactions at surfaces: from atoms to complexity. http://www.nobelprize.org/nobel_prizes/chemistry/laureates/2007/ ertl_lecture.pdf

10. Ertl G (2008) Reactions at surfaces: from atoms to complexity (nobel lecture). Angew Chem Int Ed 47(19):3524-3535. doi:10. 1002/anie.200800480

11. Sauer J (1989) Molecular models in ab initio studies of solids and surfaces: from ionic crystals and semiconductors to catalysts. Chem Rev 89:199-255

12. Pople JA (1999) Quantum chemical models (nobel lecture). Angew Chem Int Ed 38(13-14):1894-1902

13. Schröder D, Roithová J (2006) Low-temperature activation of methane: it also works without a transition metal. Angew Chem Int Ed 45(34):5705-5708. doi:10.1002/anie.200601273

14. Feyel S, Döbler J, Höckendorf R, Beyer MK, Sauer J, Schwarz H (2008) Activation of methane by oligomeric $\left(\mathrm{Al}_{2} \mathrm{O}_{3}\right)_{\mathrm{x}}+(-$ $\mathrm{x}=3,4,5)$ : the role of oxygen-centered radicals in thermal hydrogen-atom abstraction. Angew Chem Int Ed 47(10): 1946-1950. doi:10.1002/anie.200704791

15. Lunsford JH (1995) The catalytic oxidative coupling of methane. Angew Chem Int Ed 34(9):970-980. doi:10.1002/anie. 199509701

16. Kondratenko EV, Baerns M (2008) Oxidative coupling of methane. In: Ertl HK G, Schüth F, Weitkamp J (eds) Handbook of heterogeneous catalysis, vol 6, 2nd edn. Wiley-VCH, Weinheim

17. Driscoll DJ, Martir W, Wang JX, Lunsford JH (1985) Formation of gas-phase methyl radicals over $\mathrm{MgO}$. J Am Chem Soc 107:58-63

18. Ito T, Wang J, Lin CH, Lunsford JH (1985) Oxidative dimerization of methane over a lithium-promoted magnesium oxide catalyst. J Am Chem Soc 107(18):5062-5068. doi:10.1021/ ja00304a008

19. Dietl N, Schlangen M, Schwarz H (2012) Thermal hydrogenatom transfer from methane: the role of radicals and spin states in oxo-cluster chemistry. Angew Chem Int Ed 51(23):5544-5555. doi:10.1002/anie.201108363

20. Kwapien K (2011) Active sites for methan activation in $\mathrm{MgO}$ and Li-doped $\mathrm{MgO}$. Doctoral thesis, Humboldt University

21. Kwapien K, Paier J, Sauer J, Geske M, Zavyalova U, Horn R, Schwach P, Trunschke A, Schlögl R (2014) Sites for methane 
activation on lithium-doped magnesium oxide surfaces. Angew Chem Int Ed 53(33):8774-8778. doi:10.1002/anie.201310632

22. Kwapien K, Sierka M, Döbler J, Sauer J, Haertelt M, Fielicke A, Meijer G (2011) Structural diversity and flexibility of $\mathrm{MgO}$ gasphase clusters. Angew Chem Int Ed 50(7):1716-1719. doi:10. 1002/anie. 201004617

23. Kwapien K, Sierka M, Döbler J, Sauer J (2010) Reactions of $\mathrm{H}_{2}$, $\mathrm{CH}_{4}, \mathrm{C}_{2} \mathrm{H}_{6}$, and $\mathrm{C}_{3} \mathrm{H}_{8}$ with $\left[(\mathrm{MgO})_{\mathrm{n}}\right]^{+}$clusters studied by density functional theory. ChemCatChem 2(7):819-826. doi:10.1002/ cctc. 201000118

24. Schröder D, Roithova J, Alikhani E, Kwapien K, Sauer J (2010) Preferential activation of primary $\mathrm{C}-\mathrm{H}$ bonds in the reactions of small alkanes with the diatomic $\mathrm{MgO}^{+}$cation. Chem-Eur $\mathrm{J}$ 16:4110-4119

25. Muzykantov VS, Shestov AA, Ehwald H (1995) Mechanisms of catalytic activation of methane and ethylene on magnesia surface elucidated by isotopic kinetics. Catal Today 24(3):243-244. doi:10.1016/0920-5861(95)00032-B

26. Sinev MY, Bychkov VY, Korchak VN, Krylov OV (1990) Oxidative coupling of methane with participation of oxide catalyst lattice oxygen. Catal Today 6(4):543-549. doi:10.1016/09205861(90)85050-X

27. Sun J, Thybaut JW, Marin GB (2008) Microkinetics of methan oxidative coupling. Catal Today 137:90-102

28. Arndt S, Simon U, Heitz S, Berthold A, Beck B, Görke O, Epping JD, Otremba T, Aksu Y, Irran E, Laugel G, Driess M, Schubert $\mathrm{H}$, Schomäcker R (2011) Li-doped MgO from different preparative routes for the oxidative coupling of methane. Top Catal 54(16-18):1266-1285. doi:10.1007/s11244-011-9749-z

29. Myrach P, Nilius N, Levchenko SV, Gonchar A, Risse T, Dinse KP, Boatner LA, Frandsen W, Horn R, Freund HJ, Schlögl R, Scheffler M (2010) Temperature-dependent morphology, magnetic and optical properties of Li-doped $\mathrm{MgO}$. ChemCatChem 2:854-862

30. Rozanska X, Fortrie R, Sauer J (2007) Oxidative dehydrogenation of propane by monomeric vanadium oxide sites on silica. J Phys Chem C 111:6041-6050

31. Feyel S, Döbler J, Schröder D, Sauer J, Schwarz H (2006) Thermal activation of methane by tetranuclear $\left[\mathrm{V}_{4} \mathrm{O}_{10}\right]^{+}$. Angew Chem Int Ed 45:4681-4685

32. Rozanska X, Sauer J (2009) Oxidative dehydrogenation of hydrocarbons by $\mathrm{V}_{3} \mathrm{O}_{7}{ }^{+}$compared to other vanadium oxide species. J Phys Chem A 113:11586-11594

33. Feyel S, Schröder D, Rozanska X, Sauer J, Schwarz H (2006) Gas phase oxidation of propane and 1-butene with $\mathrm{V}_{3} \mathrm{O}_{7}{ }^{+}$: experiment and theory in concert. Angew Chem Int Ed 45:4677-4681

34. Sauer J, Döbler J (2004) Structure and reactivity of $\mathrm{V}_{2} \mathrm{O}_{5}$ : bulk solid, nanosized clusters, species supported on silica and alumina, cluster cations and anions. Dalton Trans 19:3116-3121

35. Paier J, Penschke C, Sauer J (2013) Oxygen defects and surface chemistry of ceria: quantum chemical studies compared to experiment. Chem Rev 113(6):3949-3985. doi:10.1021/ cr3004949

36. Pauling L (1960) The nature of the chemical bond and the structure of molecules and crystals: an introduction to modern structural chemistry, 3rd edn. Cornell University, New York

37. Winkelmann F, Wohlrab S, Libuda J, Bäumer M, Cappus D, Menges M, Al-Shamery K, Kuhlenbeck H, Freund HJ (1994) Adsorption on oxide surfaces: structure and dynamics. Surf Sci 307-309(Part 2):1148

38. Wichtendahl R, Rodriguez-Rodrigo M, Härtel U, Kuhlenbeck H, Freund HJ (1999) Thermodesorption of CO and NO from vacuum-cleaved $\mathrm{NiO}(100)$ and $\mathrm{MgO}(100)$. Phys Status Solidi A 173(1):93-100. doi:10.1002/(sici)1521-396x(199905)173:1<93: aid-pssa93 $>3.0$. co;2-4
39. Sterrer M, Risse T, Heyde M, Rust H-P, Freund H-J (2007) Crossover from three-dimensional to two-dimensional geometries of $\mathrm{Au}$ nanostructures on thin $\mathrm{MgO}(001)$ films: a confirmation of theoretical predictions. Phys Rev Lett 98(20):206103

40. Yulikov M, Sterrer M, Heyde M, Rust HP, Risse T, Freund H-J, Pacchioni G, Scagnelli A (2006) Binding of single gold atoms on thin $\mathrm{MgO}(001)$ films. Phys Rev Lett 96(14):146804

41. Nambu A, Graciani J, Rodriguez JA, Wu Q, Fujita E, Sanz JF (2006) $\mathrm{N}$ doping of $\mathrm{TiO}_{2}(110)$ : photoemission and densityfunctional studies. J Chem Phys 125(9):094706

42. Rodriguez JA, Hanson JC, Kim J-Y, Liu G, Iglesias-Juez A, Fernández-García M (2003) Properties of $\mathrm{CeO}_{2}$ and $\mathrm{Ce}_{1-\mathrm{x}} \mathrm{ZrxO}_{2}$ nanoparticles: $\mathrm{X}$-ray absorption near-edge spectroscopy, density functional, and time-resolved X-ray diffraction studies. J Phys Chem B 107(15):3535-3543. doi:10.1021/jp022323i

43. Risse T, Hill T, Beckendorf M, Katter UJ, Schlienz H, Hamann H, Freund H-J (1996) Electron spin resonance spectroscopic investigation of the rotational motion of self-assembled fatty acid films on $\mathrm{Al}_{2} \mathrm{O}_{3} / \mathrm{NiAl}(110)$. Langmuir 12:5512-5514

44. Gonchar A, Risse T, Freund H-J, Giordano L, Di Valentin C, Pacchioni $\mathrm{G}$ (2011) Activation of oxygen on $\mathrm{MgO}: \mathrm{O}_{2}{ }^{-}$radical ion formation on thin, metal-supported $\mathrm{MgO}(001)$ films. Angew Chem Int Ed 50(11):2635-2638. doi:10.1002/anie.201005729

45. Sterrer M, Risse T, Martinez Pozzoni U, Giordano L, Heyde M, Rust H-P, Pacchioni G, Freund H-J (2007) Control of the charge state of metal atoms on thin $\mathrm{MgO}$ films. Phys Rev Lett 98(9):096107

46. Yudanov I, Pacchioni G, Neyman K, Rösch N (1997) Systematic density functional study of the adsorption of transition metal atoms on the $\mathrm{MgO}(001)$ surface. J Phys Chem B 101(15):2786-2792. doi:10.1021/jp962487x

47. Del Vitto A, Pacchioni G, Delbecq F, Sautet P (2005) Au atoms and dimers on the $\mathrm{MgO}(100)$ surface: a DFT study of nucleation at defects. J Phys Chem B 109(16):8040-8048

48. Barcaro G, Fortunelli A (2005) The interaction of coinage metal clusters with the $\mathrm{MgO}(100)$ surface. J Chem Theory Comput 1(5):972-985. doi:10.1021/ct050073e

49. Jiang L, Xu Q (2005) Reactions of gold atoms and small clusters with $\mathrm{CO}$ : infrared spectroscopic and theoretical characterization of $\mathrm{Au}_{\mathrm{n}} \mathrm{CO}(n=1-5)$ and $\mathrm{Au}_{\mathrm{n}}(\mathrm{CO})_{2}(n=1,2)$ in solid argon. J Phys Chem A 109(6):1026-1032. doi:10.1021/jp045681p

50. Bonzel HP (1988) Alkali-metal-affected adsorption of molecules on metal-surfaces. Surf Sci Rep 8(2):43-125

51. Diehl RD, McGrath R (1996) Structural studies of alkali metal adsorption and coadsorption on metal surfaces. Surf Sci Rep 23(2-5):43-171. doi:10.1016/0167-5729(95)00010-0

52. Kliewer J, Berndt R (2001) Low temperature scanning tunneling microscopy of $\mathrm{Na}$ on $\mathrm{Cu}(111)$. Surf Sci 477(2-3):250-258. doi:10.1016/S0039-6028(01)00891-3

53. Giordano L, Cinquini F, Pacchioni G (2006) Tuning the surface metal work function by deposition of ultrathin oxide films: density functional calculations. Phys Rev B 73(4):045414

54. Pacchioni G, Giordano L, Baistrocchi M (2005) Charging of metal atoms on ultrathin $\mathrm{MgO} / \mathrm{Mo}(100)$ films. Phys Rev Lett 94(22):226104

55. Ricci D, Bongiorno A, Pacchioni G, Landman U (2006) Bonding trends and dimensionality crossover of gold nanoclusters on metal-supported MgO thin films. Phys Rev Lett 97(3):036106

56. Lin X, Nilius N, Freund HJ, Walter M, Frondelius P, Honkala K, Häkkinen H (2009) Quantum well states in two-dimensional gold clusters on $\mathrm{MgO}$ thin films. Phys Rev Lett 102(20):206801

57. Kittel C (1996) Introduction to solid state physics, 7th edn. Wiley, New York

58. Walter M, Frondelius P, Honkala K, Häkkinen H (2007) Electronic structure of $\mathrm{MgO}$-supported $\mathrm{Au}$ clusters: quantum dots 
probed by scanning tunneling microscopy. Phys Rev Lett 99(9):096102

59. Giordano L, Pacchioni G (2011) Oxide films at the nanoscale: new structures, new functions, and new materials. Acc Chem Res 44(11):1244-1252. doi:10.1021/ar200139y

60. Nilius N (2009) Properties of oxide thin films and their adsorption behavior studied by scanning tunneling microscopy and conductance spectroscopy. Surf Sci Rep 64(12):595-659

61. Pacchioni G, Freund H (2012) Electron transfer at oxide surfaces. The $\mathrm{MgO}$ paradigm: from defects to ultrathin films. Chem Rev 113(6):4035-4072. doi:10.1021/cr3002017

62. Nilius N, Ganduglia-Pirovano MV, Brázdová V, Kulawik M, Sauer J, Freund HJ (2008) Counting electrons transferred through a thin alumina film into Au chains. Phys Rev Lett 100(9):096802

63. Wendt S, Sprunger PT, Lira E, Madsen GKH, Li Z, Hansen JØ, Matthiesen J, Blekinge-Rasmussen A, Lægsgaard E, Hammer B, Besenbacher F (2008) The role of interstitial sites in the Ti3d defect state in the band gap of titania. Science 320(5884): 1755-1759. doi:10.1126/science. 1159846

64. Kim HY, Lee HM, Pala RGS, Shapovalov V, Metiu H (2008) CO oxidation by rutile $\mathrm{TiO}_{2}(110)$ doped with $\mathrm{V}, \mathrm{W}, \mathrm{Cr}, \mathrm{Mo}$, and $\mathrm{Mn}$. J Phys Chem C 112(32):12398-12408. doi:10.1021/jp802296g

65. Shapovalov V, Metiu H (2007) Catalysis by doped oxides: CO oxidation by $\mathrm{Au}_{\mathrm{x}} \mathrm{Ce}_{1-\mathrm{x}} \mathrm{O}_{2}$. J Catal 245(1):205-214. doi:10.1016/ j.jcat.2006.10.009

66. Shao X, Prada S, Giordano L, Pacchioni G, Nilius N, Freund H-J (2011) Tailoring the shape of metal ad-particles by doping the oxide support. Angew Chem Int Ed 50(48):11525-11527. doi:10. 1002/anie.201105355

67. Stavale F, Shao X, Nilius N, Freund H-J, Prada S, Giordano L, Pacchioni G (2012) Donor characteristics of transition-metaldoped oxides: Cr-doped $\mathrm{MgO}$ versus Mo-doped $\mathrm{CaO}$. J Am Chem Soc 134(28):11380-11383. doi:10.1021/ja304497n

68. Li B, Metiu H (2010) DFT studies of oxygen vacancies on undoped and doped $\mathrm{La}_{2} \mathrm{O}_{3}$ surfaces. J Phys Chem C 114(28):12234-12244. doi:10.1021/jp103604b

69. Hu Z, Li B, Sun X, Metiu H (2011) Chemistry of doped oxides: the activation of surface oxygen and the chemical compensation effect. J Phys Chem C 115(7):3065-3074. doi:10.1021/jp110333z

70. Shao X, Nilius N, Freund H-J (2012) Li/Mo codoping of $\mathrm{CaO}$ films: a means to tailor the equilibrium shape of $\mathrm{Au}$ deposits. J Am Chem Soc 134(5):2532-2534. doi:10.1021/ja211396t

71. Cui Y, Shao X, Baldofski M, Sauer J, Nilius N, Freund H-J (2013) Adsorption, activation, and dissociation of oxygen on doped oxides. Angew Chem Int Ed 52(43):11385-11387. doi:10. 1002/anie.201305119

72. Stipe BC, Rezaei MA, Ho W, Gao S, Persson M, Lundqvist BI (1997) Single-molecule dissociation by tunneling electrons. Phys Rev Lett 78(23):4410-4413

73. Cui Y, Nilius N, Freund H-J, Prada S, Giordano L, Pacchioni G (2013) Controlling the charge state of single Mo dopants in a CaO film. Phys Rev B 88(20):205421

74. Schwach P, Willinger MG, Trunschke A, Schlögl R (2013) Methane coupling over magnesium oxide: how doping can work. Angew Chem Int Ed 52(43):11381-11384. doi:10.1002/anie. 201305470

75. Bond GC (2005) Metal-catalysed reactions of hydrocarbons. Springer, New York

76. Somorjai GA (1994) Introduction to surface chemistry and catalysis. John Wiley \& Sons Inc, New York

77. Horiuti J, Miyahara K (1968) Report NSRDS-NBC No. 13

78. Thomson SJ, Webb G (1976) Catalytic hydrogenation of olefins on metals: a new interpretation. J Chem Soc Chem Commun 13:526-527. doi:10.1039/C39760000526
79. Johnson AD, Maynard KJ, Daley SP, Yang QY, Ceyer ST (1991) Hydrogen embedded in $\mathrm{Ni}$ : production by incident atomic hydrogen and detection by high-resolution electron energy loss. Phys Rev Lett 67(7):927

80. Doyle AM, Shaikhutdinov SK, Jackson SD, Freund H-J (2003) Hydrogenation on metal surfaces: why are nanoparticles more active than single crystals? Angew Chem Int Ed 42(42): 5240-5243. doi:10.1002/anie.200352124

81. Teschner D, Borsodi J, Wootsch A, Révay Z, Hävecker M, KnopGericke A, Jackson SD, Schlögl R (2008) The roles of subsurface carbon and hydrogen in palladium-catalyzed alkyne hydrogenation. Science 320:86-89

82. Mönch W (1995) Semiconductor Surfaces and interfaces, vol 26. Springer, Berlin

83. Wilde M, Fukutani K, Ludwig W, Brandt B, Fischer J-H, Schauermann S, Freund HJ (2008) Influence of carbon deposition on the hydrogen distribution in Pd nanoparticles and their reactivity in olefin hydrogenation. Angew Chem Int Ed 47(48): 9289-9293

84. Brandt B, Ludwig W, Fischer J-H, Libuda J, Zaera F, Schauermann S (2009) Conversion of cis- and trans-2-butene with deuterium on a $\mathrm{Pd} / \mathrm{Fe}_{3} \mathrm{O}_{4}$ model catalyst. J Catal 265(2):191-198

85. Neyman KM, Schauermann S (2010) Hydrogen diffusion into palladium nanoparticles: pivotal promotion by carbon13. Angew Chem Int Ed 49(28):4743-4746

86. Ludwig W, Savara A, Schauermann S, Freund H-J (2010) Role of low-coordinated surface sites in olefin hydrogenation: a molecular beam study on Pd nanoparticles and $\mathrm{Pd}(111)$. ChemPhysChem 11(11):2319-2322. doi:10.1002/cphc.201000355

87. Lu JL, Weissenrieder J, Kaya S, Gao H-J, Shaikhutdinov S, Freund H-J (2007) Structure, thermal stability, and CO adsorption properties of Pd nanoparticles supported on an ultra-thin $\mathrm{SiO}_{2}$ film. Surf Rev Lett 14(05):927-934. doi:10.1142/S0218625X07010469

88. Horiuti J, Polanyi M (1934) Trans Faraday Soc 30:1164

89. Ludwig W, Savara A, Dostert K-H, Schauermann S (2011) Olefin hydrogenation on Pd model supported catalysts: new mechanistic insights. J Catal 284(2):148-156. doi:10.1016/j.jcat.2011.10.010

90. Hansen KH, Worren T, Stempel S, Lægsgaard E, Bäumer M, Freund HJ, Besenbacher F, Stensgaard I (1999) Palladium nanocrystals on $\mathrm{Al}_{2} \mathrm{O}_{3}$ : structure and adhesion energy. Phys Rev Lett 83(20):4120-4123

91. Wilde M, Fukutani K, Naschitzki M, Freund HJ (2008) Hydrogen absorption in oxide-supported palladium nanocrystals. Phys Rev B 77(11):113412

92. Salmeron M, Schlögl R (2008) Ambient pressure photoelectron spectroscopy: a new tool for surface science and nanotechnology. Surf Sci Rep 63(4):169-199. doi:10.1016/j.surfrep.2008.01.001

93. Heinz TF (1991) Second-order nonlinear optical effects at surfaces and interfaces. In: Ponath H-E, Stegemen GI (eds) Nonlinear surface electromagnetic phenomena, vol 29. Elsevier, Amsterdam, p 353-416.

94. Rasmussen PB, Hendriksen BLM, Zeijlemaker H, Ficke HG, Frenken JWM (1998) The "Reactor STM": a scanning tunneling microscope for investigation of catalytic surfaces at semi-industrial reaction conditions. Rev Sci Instrum 69(11):3879-3884. doi: $10.1063 / 1.1149193$

95. Creemer JF, Helveg S, Hoveling GH, Ullmann S, Molenbroek AM, Sarro PM, Zandbergen HW (2008) Atomic-scale electron microscopy at ambient pressure. Ultramicroscopy 108(9):993-998. doi:10.1016/j.ultramic.2008.04.014 